\title{
La difusión manuscrita temprana del Buscón de Quevedo, a la luz de una noticia de época desatendida*
}

\section{Handwritten Early Dissemination of Quevedo's Buscón, in the Light of Unattended Contemporary News}

\author{
María José Alonso Veloso \\ Universidad de Santiago de Compostela \\ mariajose.alonso@usc.es \\ ORCID iD: https://orcid.org/0000-0002-9666-5626
}

\section{RESUMEN}

El objetivo de este artículo es recuperar el contenido de una carta del siglo XVII, conservada en la biblioteca de la Real Academia de la Historia. Su interés reside en el hecho de contener datos que obligan a reconsiderar la idea de que el Buscón de Quevedo conoció una temprana y profusa difusión manuscrita, previa a la publicación de su primera edición zaragozana, en 1626. La carta es también un temprano testimonio de época sobre la recepción de la obra picaresca en Madrid: se trata del primer juicio crítico conservado sobre ella. Adicionalmente, permite aventurar que en tal lugar pudo haber circulado de forma simultánea, o incluso previa a la princeps, otra edición que difería de ella al menos en el detalle de la promesa de una segunda parte que solo figura en la tradición manuscrita.

Palabras Clave: Buscón; Quevedo; 1626; transmisión manuscrita temprana; recepción en Madrid.

\section{ABSTRACT}

The aim of this article is to recover a 17th-century letter, preserved in the library of the Real Academia de la Historia. Its interest lies in the fact that the manuscript includes some information

* Este artículo es resultado de los proyectos de investigación «Edición crítica y anotada de la obra en prosa de Quevedo, IX» (MINECO, Excelencia 2015, FFI2015-64389-P; AEI/ FEDER, UE) y «Edición crítica y anotada de la poesía completa de Quevedo, 1: las silvas» (PGC2018-093413-B-I00; AEI/FEDER, UE), del Programa Estatal de Generación del Conocimiento, del Ministerio de Ciencia, Innovación y Universidades. Ha contado también con financiación del Programa de Consolidación y Estructuración de Unidades de Investigación Competitivas de la Xunta de Galicia para el año 2018, «Grupo GI-1373, Edición crítica y anotada de las obras completas de Quevedo (EDIQUE)» (ED431B 2018/11). 
about Quevedo's Buscón. According to its text, scholars should reconsider the idea that this work had an early and profuse handwritten diffusion, previous to the first edition, published in Zaragoza in 1626. The letter is also an early testimony about the reception of the picaresque novel in Madrid at that time: it is the first critical judgment about the Buscón. In addition, it can be inferred from this letter that another edition could have circulated simultaneously, or even prior to the princeps in that place. That unknown edition differed from the other at least for having included a promise about a forthcoming second part, a detail that was only mentioned in manuscript tradition.

Key words: Buscón; Quevedo; 1626; Early handwritten transmission; Reception in Madrid.

El presente artículo analiza una carta manuscrita del siglo XVII, conservada en la Real Academia de la Historia. Olvidada en uno de los volúmenes con papeles de jesuitas, atesora valiosa información sobre el contexto histórico, político y literario, en la década de los años veinte, en el Madrid de Felipe IV: en concreto, alude a hechos datados entre 1625 y 1626 . Remitente y destinatario se mantienen en el anonimato, pero la fórmula de tratamiento utilizada, «vuestra señoría», y el propio contenido traslucen su perfil de cortesanos próximos a los círculos de poder. Su autor desgrana una serie de noticias que entrecruzan política exterior española y acuerdos matrimoniales entre familias de la nobleza; que protagonizan figuras de relieve en la época como Spinola, el inquisidor Zapata, Olivares, Lerma, Monterrey, Lemos o Chinchón; que comentan, en fin, novedades literarias tan notables como la reciente impresión de la nueva obra de Quevedo: el Buscón ${ }^{1}$. La epístola no solo ofrece datos interesantes sobre la difusión impresa de la obra picaresca, sino que constituye un precioso testimonio de su recepción en Madrid: consiste parcialmente en un ejercicio de «crítica literaria» sobre el Buscón, en cuyos comentarios se adivinan el interés que los escritos de Quevedo suscitaban en el ámbito de la Corte $\mathrm{y}$, tal vez, un temprano indicio de las polémicas e invectivas que muy pronto se desatarían contra sus obras, denunciadas ante la Inquisición. Tomando en consideración dicho documento, este artículo persigue los siguientes objetivos:

1. Reproducir íntegramente la carta, rica en datos sobre personajes y hechos históricos acaecidos mediada la década de los años veinte del siglo XVII: citada parcial y fugazmente hace casi un siglo por uno de los primeros editores modernos de Quevedo (Luis Astrana Marín), su existencia y la información reveladora que ofrece han pasado sorprendentemente desapercibidas en estudios posteriores.

1 «[El Buscón] entra en esa categoría de literatura volcada hacia el referente, en este caso la vida de Corte, sus tipos y problemas. Sin duda, el Buscón parece encerrar también alusiones veladas a personajes y hechos que ahora no percibimos con claridad» (Rey 2014, 13-14). Es plausible que tal mensaje cifrado explique en parte la expectación con la que Madrid recibe los ejemplares de la obra, como se verá. 
2. Reconstruir el contexto del intercambio epistolar a partir de personajes $\mathrm{y}$ hechos aludidos en la carta, cuyo texto se transcribe, acompañado de notas.

3. Reconsiderar la creencia de que existió una difusión manuscrita temprana del Buscón, previa a 1626. De haberse tratado de una obra ya conocida, el remitente no habría anunciado la obra impresa como una estricta novedad, un «aviso» reseñable, ni habría aportado detalles sobre su contenido y estilo, en relación con obras previas de Quevedo. Según todos los indicios, tales pormenores, como el propio relato picaresco, eran aún desconocidos en el momento de escritura de la carta.

4. Postular la hipótesis de que la que conocemos como princeps de 1626 no sea tal o que, al menos, hubiese existido otra impresión desconocida en torno a la misma fecha o incluso antes, con variantes respecto a aquella, diferente de las conocidas y ya descritas. La edición a la que apunta la carta incluiría el anuncio final de una futura segunda parte del Buscón, ausente en la edición zaragozana y en las derivadas de ella: al menos en este aspecto, coincidiría con los tres manuscritos de la tradición textual.

5. Proponer la mencionada misiva como primer texto «crítico» en torno al Buscón: una opinión personal, desfavorable, que precede a la larga cadena de diatribas que atacaron el relato picaresco por su carácter irreverente desde un punto de vista religioso. Exenta de la ferocidad de las invectivas contra Quevedo de los años 20 y 30 del siglo XVII, y ajena en apariencia a sus graves propósitos (su carácter privado la apartó de la difusión pública que registraron las otras), expresa no obstante un juicio muy negativo sobre la calidad literaria de la obra.

\section{DESCRIPCIÓN DE LA CARTA}

La carta se encuentra en un manuscrito custodiado en la Real Academia de la Historia e integrado por tres hojas con un tamaño de $31 \times 20 \mathrm{~cm}$., que pertenece a la colección de «Papeles de Jesuitas», configurada en general por volúmenes facticios como el tomo 75 , donde se incluye la carta, identificada con la signatura M-RAH, 9/3649. El contenido es misceláneo: se trata de 125 ítems según el índice manuscrito antiguo (dos más según el cómputo corregido posterior), entre los cuales se cuentan numerosos memoriales, cartas, relaciones, alegaciones, y otros escritos, de contenido histórico o circunstancial, con predominante carácter político y religioso. Aunque la carta objeto de análisis está manuscrita, en el volumen hay numerosos impresos en pliegos sueltos, alguno relativo a la polémica en torno al patronato de Santiago. La datación mayoritaria de los documentos comprende la década de los años 20 del siglo XVII, ya con Felipe IV como monarca, con predominio de las fechas 1625 , 
1626,1627 y 1628 , aunque no faltan, al comienzo y al final del volumen, casos más tempranos, datados al principio del siglo XVII o en los años 60 y 70 del siglo XVI.

Frente al detalle del índice, que especifica cada uno de los contenidos del tomo, con referencia a su condición de manuscrito o impreso, además del título, la fecha y el lugar, llama la atención el epígrafe impreciso y poco informativo que sintetiza en una única referencia los ítems 36 a 58, donde se encuentra la carta, con el número 44: "Varias copias de cartas con noticias particulares y de poco interés. Ms. en folio», valoración negativa que pudo haber contribuido a su nula difusión ${ }^{2}$.

Escrita con letra clara y la misma caligrafía y tinta, la carta refleja, no obstante, la premura con que el remitente redacta su última parte, donde desgrana los episodios del relato picaresco. La prisa se deriva de lo que cuenta a su interlocutor: ya se había resignado a enviarle la carta sin adjuntarle el ejemplar del Buscón, porque no se lo había devuelto aún la persona a quien lo había prestado previamente, pero consigue recuperarlo y mandarlo, debido al retraso que sufre el correo a causa de las inclemencias del tiempo. Tales avatares parecen explicar que la caligrafía de la última hoja, en blanco en su verso, y también el final de la anterior, tenga trazos más rápidos y descuidados.

La carta carece por lo general de tachaduras, aunque existe una aparente censura, tal vez posterior: en la segunda hoja, poco antes de la referencia al Buscón, las dos líneas finales de un párrafo fueron tachadas y resultan ilegibles, no en vano mencionan las estrategias de Lerma respecto a Olivares, los Carpio y la localidad andaluza de Adamuz - que acogió la jornada real de Felipe IV en 1624-y, antes del pasaje censurado, la frase de probable tono irónico «con todas estas cosas está muy en su punto la santidad del Conde y hay públicas alabanzas della».

El manuscrito carece tanto de epígrafes como de referencias a su posible autor ni tampoco al destinatario, pero está registrado con el título [Avisos de Madrid de 1626]: en efecto, posee la característica estructura de los «avisos» de época, gacetas que ciertos escritores del siglo XVII elaboraban en la Corte, para después enviarlas por correo de postas a algún noble distante, con el objetivo de informarle sobre las novedades más interesantes producidas en su ausencia ${ }^{3}$.

2 Agradezco a Asunción Miralles de Imperial y Pasqual del Pobil, de la Biblioteca de la Real Academia de la Historia, su ayuda tanto para la consulta de la carta como la del índice manuscrito antiguo del volumen.

${ }^{3}$ Los más conocidos en esta época, considerados precursores del periodismo, fueron Andrés de Almansa y Mendoza, Jerónimo de Barrionuevo y José Pellicer de Ossau; ningún dato me permite adscribir la carta con seguridad a uno de ellos. Sobre su actividad y este tipo de documentos, pueden consultarse Ettinghausen (2012 y 2015), y Ettinghausen y Borrego (2001), entre otros. 

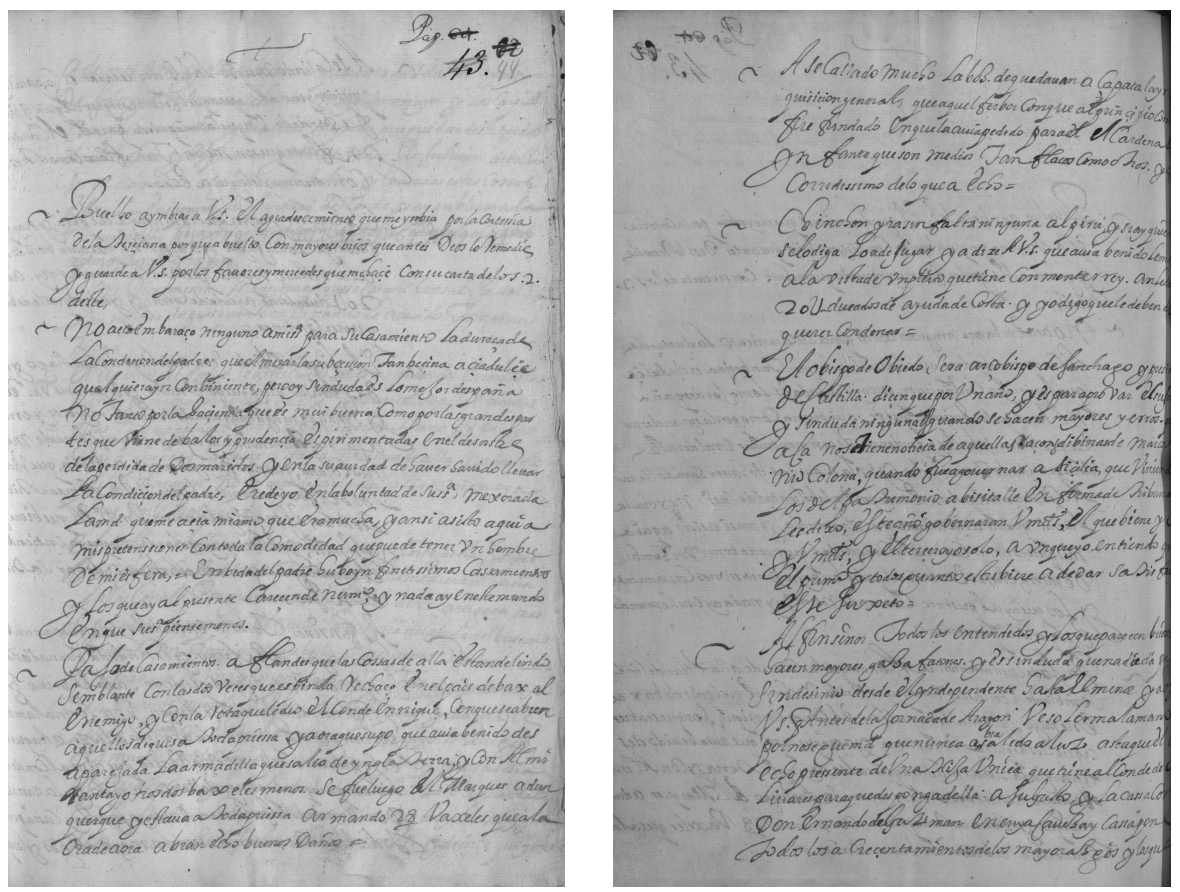

LÁminas 1 y 2. Comienzo del manuscrito, con noticias sociales y políticas.

Fuente: Biblioteca de la Real Academia de la Historia, M-RAH, 9/3649.

La escueta información que consta en la catalogación de la biblioteca contiene una fecha: 1626. Se basa en la que figura en la segunda hoja y en la referencia explícita a la noticia de la reciente publicación del Buscón en Zaragoza, «citada entre los avisos», cuya primera edición conocida salió de la imprenta ese mismo año. El catálogo de la biblioteca sugiere esa fecha a partir del propio documento, y es la que parece más plausible. No obstante, no se lee con la claridad deseable: por situarse al final de la línea y del margen derecho del folio, y por haber traspasado la tinta de algún trazo del vuelto de la hoja, que se transparenta por debajo de los números del año. Se puede afirmar que el trazo del segundo número del año es un 6 con total seguridad, con la parte abierta hacia la derecha, pero, con todas las cautelas imprescindibles en estos casos, difiere del que tiene el último número, que podría ser también un 6 trazado de modo diferente o bien un 5 , a juzgar por una abertura del número hacia el lado contrario, la izquierda. La eventualidad de una edición a finales de 1625 , o difundida en 1625 pero con fecha de 1626, necesitaría mayores indagaciones. Pero lo sorprendente es que algunos de los episodios históricos mencionados en la carta, relacionados con el papel político y militar de España en el contexto europeo, parecen apuntar hacia 1625: como se mostrará 
después, ciertos hechos solo podrían calificarse como estricta novedad ese año; eran «avisos» del remitente -que asume el papel de «cronista» y se muestra ampliamente informado- sobre acontecimientos que su interlocutor no conocía ese año por no ser aún de dominio público. En diciembre de 1626, por el contrario, ya no serían noticia.

\section{Historia DE UN HALLAZGO Y UN OLVIDO CRÍTICO}

Pese al interés patente de la carta, su contenido no ha sido tenido en cuenta por los críticos que han editado o estudiado la obra, si se exceptúa el caso de Astrana. Este editor relegó la noticia de su existencia a un comentario inserto en su edición de las Obras en verso de Quevedo (primer tomo de las Obras completas), en el año 1932, en un prólogo dedicado a los textos y fuentes de los escritos quevedianos. En la primera parte de tal introducción, ofrece información sobre la prosa, antes de detenerse en la lírica; en decimonoveno lugar, el editor comenta la fecha y el proceso de escritura del Buscón. Refiriéndose a la recepción de la obra, deja testimonio de la localización de un documento manuscrito con un juicio crítico muy negativo, de autor desconocido, que «ha permanecido oculto hasta ahora, en que sale anónimo, doble castigo que ha dado tiempo a su osadía» (Astrana 1932, XXIII). El editor pondera su interés extraordinario y vaticina su futura presencia en toda edición de la obra que se realice 4 . Astrana (1932, XXIV) transcribe parcialmente la carta y arremete contra «el ilustre enfermo de tercianas» que escribió la misiva, en particular por sus palabras contra la prolijidad y falta de gracia del pasaje sobre el pupilaje en casa del célebre Cabra. Sin ofrecer más explicaciones, finaliza llamando la atención sobre la rareza del comentario del remitente de la carta relativo a la prometida segunda parte del Buscón $n^{5}$.

Aunque apreció el interés de la carta, Astrana no analizó el documento del que tuvo noticia y ofreció solo información parcial del mismo; tampoco intentó dilucidar el momento de la escritura, basándose en los hechos históricos aludidos en el fragmento previo a la referencia del Buscón, que omite íntegramente, si es que conoció esa parte de la epístola; no ahondó en la discrepancia que advirtió en el final de la obra, ni indagó en la posible existencia de ediciones simultáneas o incluso anteriores a la princeps conocida. Pudieron influir en

4 «El valiosísimo documento, que ya no podrá faltar en ninguna edición del Buscón, es una carta, escrita en Madrid por personaje de relieve y dirigida a otra de no menor calidad (es tratada de vueseñoría), que aparece sin firma, de copia coetánea, en el códice de la Biblioteca de la Academia de la Historia, signatura 12-15-2=75, pliego 43, páginas 3. a 4. ${ }^{\mathrm{a}} \mathrm{y}$ 5." ${ }^{\mathrm{a}}$ (Astrana 1932, XXIII).

5 Según Astrana, habida cuenta de que habla sobre la primera edición de Zaragoza, en la que «se suprimieron aquellas palabras». 
su ánimo el consenso crítico sobre la fecha de la primera edición de la obra, a falta de evidencias sobre otras impresiones; y la propia catalogación del documento, datado con la fecha de la edición zaragozana, al menos en la actualidad.

Astrana se equivocaba cuando suponía que la carta tendría una importante repercusión en los estudios posteriores: pese a que son abundantes durante el siglo XX y el comienzo del $\mathrm{XXI}^{6}$, su hallazgo no ha tenido cabida en ninguno de ellos, ni siquiera en forma de rápida mención. Tampoco en los análisis sobre los juicios críticos e invectivas que proliferaron contra las obras de Quevedo en el siglo XVII y aún en vida del autor, aunque el Buscón fue una de las dianas preferidas de sus detractores, junto con Política de Dios y los Sueños, entre otros textos. La razón del olvido puede deberse al poco orden con que Astrana presentó sus hallazgos: el inesperado emplazamiento del documento en el prólogo de un volumen de obras en verso y la defectuosa información que dio en sus relaciones de documentos incluidos en el mismo libro. Es posible que también haya pesado el desprestigio que ha recaído sobre Astrana -acusado de haber introducido entre los textos quevedianos numerosos apócrifos- o la muchas veces difícil localización de los testimonios por él citados, por cambios en las signaturas (como ocurre en este caso) y dispersión o desaparición de fondos en las bibliotecas. Se añade el hecho de que el índice manual del volumen donde se inserta la carta describe de modo impreciso el contenido de la parte a la que pertenece, con un juicio negativo sobre su valor.

Ni siquiera Buendía se detiene en el manuscrito, pese a seguir en lo sustancial a Astrana para su edición de las obras completas de Quevedo. He localizado solo una única referencia indirecta, muy rápida, a la carta citada por Astrana en uno de los ensayos de Sénder (1971, 233), dedicado a otro escritor, Pío Baroja. Disertando en torno a su prolijidad, argumenta lo relativo de tal concepto en las distintas épocas, y toma como ejemplo lo sorprendente de que la misiva califique el Buscón como «un libro pesado, frío y prolijo. Insiste en la prolijidad muchas veces. "Prolijísimo"».

Si el autor que lo acusa de prolijo fuera alguno de los enemigos de Quevedo, como Pacheco o Jáuregui o Ramírez de Prado, no llamaría la atención, pero en el mismo documento el autor hace grandes elogios de Quevedo y se lamenta de que haya caído en esa triste «prolijidad» habiendo tantas veces demostrado una gran inventiva. Para un sector español del siglo XVII El Buscón podía ser pesado, tan pesado como el libro del pajarero del Rey. La cosa parece hoy absurda (Sénder 1971, 233).

Cabe matizar las palabras de Sénder. Cierto es que el documento no incurre en los insultos ni la agresividad de futuras invectivas, pero tampoco parece

${ }^{6}$ Remito al estado de la cuestión más completo y actualizado en torno al Buscón hasta la fecha, a cargo de Rey (2014). 
complaciente con el estilo de Quevedo, al menos no con el del Buscón; ni mucho menos cabe inferir los «grandes elogios» hacia el escritor que supone Sénder. De hecho, en un momento de su trayectoria literaria en el que aún tiene por delante dos décadas de intenso ejercicio profesional, en las que escribirá alguna de sus obras más reconocidas, el remitente de la carta lo considera ya un ingenio acabado, del pasado. Incluso la propia referencia parece conceder poco crédito al testimonio manuscrito, o al menos no ratifica su existencia ni su contenido; tildando de «observación divertida» la de Astrana en su prólogo, señala: «Dice Astrana Marín que ha encontrado en la biblioteca de la Academia de la Historia una carta de un ciudadano del siglo XVII dirigida a una personalidad importante» (ibíd.).

\section{NOTICIAS SOBRE PERSONAJES Y HECHOS HISTÓRICOS ENTRE 1625 Y 1626}

La carta es rica en alusiones a hechos históricos que, en algún caso, sucedieron en fechas concretas bien conocidas, protagonizados por personajes poderosos de la época. Sintetizo algunos de los datos más significativos para su datación.

\subsection{Actividad de la flota española en Flandes}

Paso de casamientos a Flandes, que las cosas de allá están de lindo semblante, con las dos veces que Espinola rechazó en el País de Bax al enemigo, y con la rota que le dio el conde Enrique, con que se abren aquellos diques a toda priesa; y ahora que supo que había venido desaparejada la armadilla que salió de Inglaterra y con almiranta y otros dos bajeles menos, se fue luego el Marqués a Dunquerque y estaba a toda priesa armando 28 bajeles que, a la hora de ahora, habrán hecho buenos daños.

El remitente parece aludir a la victoria de Spinola, artífice de la rendición de Breda, y Enrique de Bergh ante la armada inglesa, diezmada en 1625, después de que el primero hubiese instalado el cuartel general en Dunquerque, donde tenía su base «una magnífica escuadra de nuevas fragatas» (Stradling $1992,103)^{7}$. El tono heroico y triunfalista es coincidente con la etiqueta que los historiadores han asignado a 1625, annus mirabilis del reinado de Felipe IV y su valido Olivares (Elliott 1990, 234-250), en contraste con los desastres de un imperio en declive: el año en que se produjo la toma de la inexpugnable Breda y la victoria de la armada española contra los ingleses en Cádiz, entre otros logros militares (Stradling 1992, 78-86).

7 Sobre los episodios que comento a partir de este punto, pueden consultarse más detalles en las notas a pie de página, en la transcripción de la carta. 


\subsection{Posible nombramiento de Antonio Zapata como inquisidor general}

Hase callado nuevo la voz de que daban a Zapata la Inquisición General, que aquel fervor con que al principio corrió fue fundado en que la había pedido para él el Cardenal Infante, que son medios tan flacos como otros, y está corridísimo de lo que ha hecho.

El comentario desvela que el fervor desatado por la propuesta de conceder la Inquisición General a Zapata se debió a que partía del Cardenal Infante, ya arrepentido de haberla hecho. El rumor de que parece descartarse su nombramiento como inquisidor general no parece plausible al final de 1626, unos pocos días antes de que se produjese efectivamente. Antonio Zapata había asumido el arzobispado de Toledo en 1625, en coincidencia con la minoría de edad del arzobispo titular, el cardenal infante Fernando de Austria; y llegó al cargo de inquisidor general del reino al comienzo de 1627 , por efecto de una bula del papa Urbano VIII, dictada en enero de dicho año.

\subsection{Argucias de Lerma previas a la jornada de Aragón}

Ya oyó V. S. que antes de la jornada de Aragón besó Lerma la mano por no sé qué merced.

La jornada de Aragón se celebró a principios de 1626, pero se anunció a finales de 1625: en enero se inauguraron las cortes del reino de Aragón (Barbastro) y Valencia (Monzón); en marzo, las de Cataluña (Lérida) ${ }^{8}$. Las convocatorias de cortes se derivan de la Unión de Armas (Elliott 1990, 251283) y el «Gran Memorial» elevado a Felipe IV en 1624 por el Conde-Duque de Olivares (Elliott y De la Peña 1978: I, 37-100; Elliott 1990, 192-212). La carta, fechada el 9 de diciembre, se refiere a un momento previo a la celebración de las cortes, aunque en este caso serían plausibles ambos años (1625 y 1626), con la jornada ya celebrada o a punto de celebrarse. En apoyo de esta última posibilidad, puede aducirse que el autor de la carta parece anticipar en todo momento rumores, novedades, para seguro deleite de su interlocutor.

${ }^{8}$ Fueron numerosas las obras de Quevedo publicadas en Zaragoza durante su estancia con la comitiva real en Aragón entre enero y febrero de 1626, aunque sigue sin aclararse su exacta participación en un amplio proyecto editorial que, protagonizado por Verges y Duport, conllevó la impresión sucesiva de obras entre las que se encontraban Política de Dios y el Buscón. Debe observarse que la primera incluye en el pie de imprenta de la princeps zaragozana precisamente la fecha de 1625; véase la interpretación de Jauralde (1999, 506-508) para este episodio. 


\subsection{Conflicto entre España y Francia por la Valtelina}

Días ha que no hay cartas de Italia ni se sabe de allá: nada, sólo que los franceses no quieren dejar la Valtelina, ni Saboya viene en lo tratado acá.

En 1622 España había conquistado la Valtelina, garantizando la comunicación entre Italia y los Países Bajos españoles. En 1625, Francia ocupa el paso de la Valtelina, coligándose con Venecia y Saboya en contra de Génova, aliado tradicional de España; lo bloquea hasta 1626, cuando queda bajo custodia de las tropas papales. España no consigue acabar con el bloqueo de Génova y restablecer el statu quo en el paso de la Valtelina hasta 1626, con el llamado «Tratado de Monzón»; en síntesis de Stradling (1992, 85), «los franceses y saboyanos sufrieron una derrota decisiva en lo que fue prácticamente el diktat de Monzón (1626)». En la carta, los franceses siguen ocupando la Valtelina, un dato más difícil de adscribir a diciembre de 1626.

Los avatares políticos comentados apuntan tal vez hacia finales de $1625^{\circ}$, en coincidencia con la eventualidad de que la carta hubiese sido datada en diciembre de tal año y no en 1626, aunque esta última fecha sea la más probable.

\section{LA PRINCEPS DEL BUSCÓN Y SU PRESUNTA DIFUSIÓN MANUSCRITA TEMPRANA}

El Buscón es una de las obras de Quevedo que ha recibido mayor atención crítica, dentro y fuera de España. Pese a la abundancia y variedad de estudios, son muchas las dudas que aún persisten en torno a su escritura y difusión, $\mathrm{y}$ muy pocas las respuestas concluyentes. Existen, no obstante, dos opiniones más reiteradas que demostradas, pese a no estar sustentadas en datos fehacientes, sino en meras hipótesis: premisas dudosas que obstaculizan la comprensión del Buscón (Rey 2014, 16) y construyen un edificio teórico sólido solo en apariencia, pues está basado en especulaciones inciertas. La primera de ellas, la presunción de su redacción temprana, imposible de verificar con los datos actuales $\mathrm{y}$ fruto de un «prejuicio interpretativo» (Cabo 2011, 34) ${ }^{10}$ : las propuestas osci-

${ }^{9}$ Remito al diagnóstico que Felipe IV hizo de la situación en aquel año 1625 -en Flandes y Breda, respecto a Inglaterra y la Valtelina-, en su intervención ante el Consejo de Castilla de 1627 (Elliott y De la Peña 1978: I, 244-246). Sobre las circunstancias en 1624 y 1625, véase Elliott (1990, 224-250).

${ }^{10}$ Rey $(2014,16)$ : «Si nada demuestra que el Buscón es una obra de redacción muy temprana parece prematuro interpretarlo a la luz de un hecho tan dudoso, situándolo en una circunstancia vital y literaria inverificable, cuando no falsa». Cabo $(2011,34)$ advierte: «Dar por cierto que el Buscón es una obra juvenil es en lo fundamental el resultado de una construcción crítica e ideológica, instituida fundamentalmente en el siglo XIX, que, en el XX, adquiriría una notable productividad en el terreno editorial. No es tanto un hecho como un prejuicio interpretativo». 
lan entre quienes sugirieron una fecha de madurez, en torno a 1620, y quienes interpretaron el texto como producto juvenil, redactado en los primeros años del siglo XVII, entre ellos Lázaro Carreter (1969) o Jauralde (1990) ${ }^{11}$; a medio camino entre ambas propuestas, otros críticos propusieron una etapa intermedia,

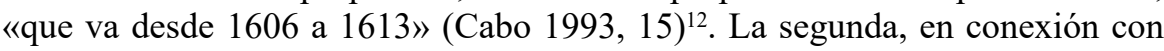
la anterior, la supuesta existencia de una poblada transmisión manuscrita, previa a la versión impresa de 1626 , en Zaragoza ${ }^{13}$ : la obra habría sido ampliamente conocida antes de su llegada a la imprenta, hipótesis basada en la existencia de tres manuscritos, presunto «testimonio de una circulación muy amplia» (Cabo 1993, 3) y con anterioridad a la primera edición.

Sobre ambas afirmaciones, reiteradas durante las últimas décadas, Rey (2014, 45) matizaba: «Suele decirse que el Buscón conoció una extensa difusión manuscrita, pero, a falta de pruebas, poco se puede decir acerca de la misma». Alertaba también sobre el riesgo de presuponer y opinar sobre la posible recepción del texto antes de 1626, debido a «la ausencia de noticias o de una transmisión indirecta», que, a su juicio «obliga a pensar que no fue conocido por el público lector» antes de dicha fecha ${ }^{14}$.

El contenido de la carta que aquí se comenta obliga a dejar en suspenso la creencia de algunos críticos acerca de la popularidad temprana del Buscón, al tiempo que parece respaldar la tesis de Rey (2010a y 2014). Las apreciaciones del «crítico» literario autor de la carta desvelan datos de interés relativos a la fecha de redacción del Buscón, aún objeto de debate, y a su presunta divulgación masiva a través de copias manuscritas tempranas. Como se ha señalado, pese a las divergencias en las fechas concretas y en los argumentos esgrimidos por la crítica, existe cierta tendencia a proponer una datación temprana para la

11 «Quevedo redactó El Buscón muy joven, probablemente poco después de llegar a Valladolid» (Jauralde 1990, 23). Previamente, Selden Rose (1927) la consideró una obra juvenil. Véase también Tobar (2011-2012).

${ }^{12}$ En síntesis de Rey $(2014,60)$ : «Entre 1605 y 1613, fecha en la que suele situarse la redacción del Buscón». Sobre la fecha de esta obra, pueden consultarse, entre otros, Cabo (1993, 1-15); Díaz Migoyo (2003, 19-36); Rey (1997 y 2007a: II, I, 34-39 y 62-63); Martín Jiménez (2008, 123-144); Cabo (2009, 229-248); Tobar (2011-2012); y Rey (2014, 35-43). Otra cuestión polémica en torno a esta obra, relacionada con el tema de este artículo pero imposible de abordar en detalle ahora, atañe a la existencia de distintas versiones de autor: dos según Lázaro Carreter (1965) o Cros (1988); una sola recogida en el manuscrito $B$ de acuerdo con Jauralde (1990); o cuatro a juicio de Rey (1994-1995, 1997, 1999, 2007a, $2007 b, 2007$ c y 2014, entre otras aportaciones).

13 « $\mathrm{Si}$, a diferencia de lo ocurrido con los Sueños y otras piezas burlescas, ningún documento prueba que el Buscón experimentó una poblada difusión manuscrita, resulta arriesgado opinar acerca de su posible recepción antes de 1626» (Rey 2014, 16).

${ }^{14}$ En el mismo sentido se había pronunciado previamente; véase Rey (2010a, XI), donde opone el caso del Buscón a lo sucedido con los Sueños: «No sólo es reveladora la escasez de copias, sino también que ninguna de ellas ofrezca trazas de una vida textual ajena al autor». 
obra picaresca: una hipotética difusión manuscrita previa habría culminado con su llegada a la imprenta en 1626. Esta carta se refiere a dicha obra, en cambio, como una radical novedad, como un «aviso» o noticia que desgrana detalles de la narración y aun traza una comparación - de la que, por cierto, sale mal parado el Buscón- con otros escritos previos de Quevedo. Tales comentarios resultarían innecesarios e injustificables de tratarse de una obra ya conocida previamente, a través de copias manuscritas.

En primer lugar, el remitente se siente en la obligación de precisar, tras el título de la obra, su autor y su asunto, propio de «su genio», es decir, concordante con las obras burlescas de difusión previa, desde comienzos del siglo XVII:

No habiendo venido desde Zaragoza más de 50 libros impresos -el título, la Historia de la vida del Buscón; el autor, don Francisco de Quevedo; el asumpto, nativo de su genio-, hube uno de ellos por mano de un teatino, con los mayores afanes del mundo, y pagué ocho reales por él.

De haberse producido una profusa circulación manuscrita previa, la noticia sería en todo caso la propia impresión, de un texto ya conocido, pero resultaría ocioso aclarar el nombre del autor. A esa altura del siglo no cabe suponer que hubiese sido posible la circulación de una obra burlesca de Quevedo, ingenio ya consagrado, sin que el ámbito cortesano tuviese conocimiento de ella.

Resulta interesante el dato de los 50 ejemplares, cifra exigua que explica la irritación del autor de la carta, cuando supone que no le van a devolver el libro que había prestado, tras haberlo conseguido con tanta dificultad. Moll (1996) se refirió a una «tirada normal de 1.500 ejemplares» en la imprenta de la España del Siglo de Oro ${ }^{15}$ : partiendo de tal cálculo, a Madrid habría llegado solo poco más del 3 por ciento de los ejemplares correspondientes a una tirada media de libros en la época. En cuanto a los ocho reales, únicamente es posible proponer una estimación basada en las características de la edición de Zaragoza de 1626, pues carecemos de información sobre la que circuló por Madrid. Compuesta en octavo, tamaño usual para la impresión de este tipo de libros en la época, su texto abarca 101 folios numerados, a los que se suman los ocupados por los preliminares y la tabla final ${ }^{16}$. El libro carece de tasa (las disposiciones legales para la actividad impresora eran menos restrictivas en Zaragoza que en Madrid), pero se puede proponer una extrapolación a partir de la que era corriente, 3 ó 4 maravedís por pliego (Reyes 2010, 45; Moll 2008) ${ }^{17}$ : la

15 Pero precisó que «el mercado español no la podía absorber en poco tiempo, en tanto que una parte de la misma era suficiente para abastecerlo».

${ }^{16}$ Sin contar el cuaderno de los preliminares, el texto del Buscón abarca las signaturas A8-M8, N6.

${ }^{17}$ La princeps de la obra de Quevedo titulada Epitome a la historia de la vida ejemplar y gloriosa muerte del bienaventurado fray Tomás de Villanueva, impresa en Madrid en 1620, se tasó «a cuatro maravedíes el pliego». 

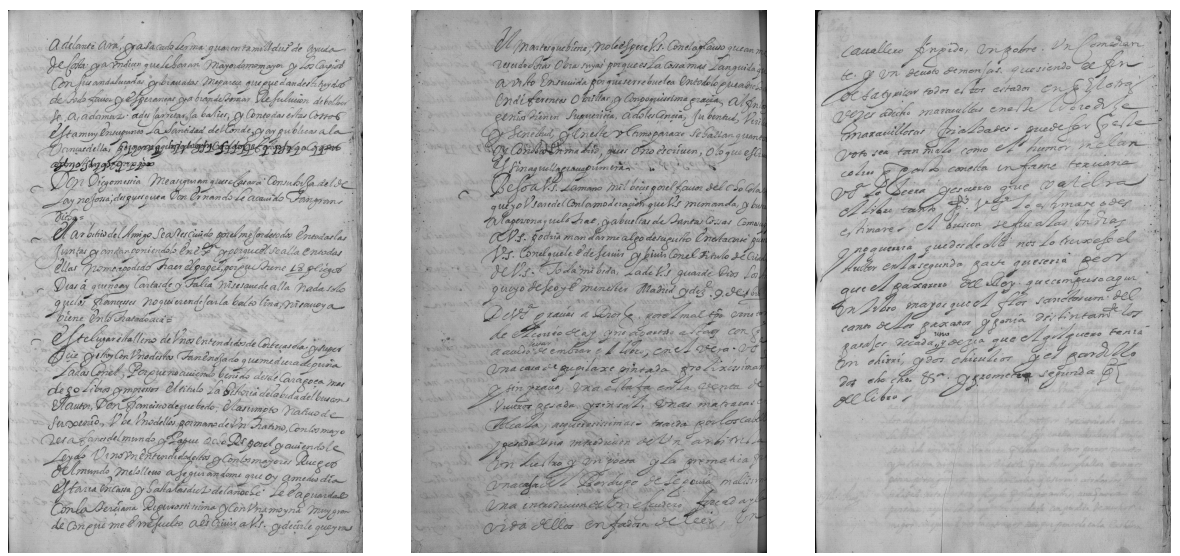

LÁmINAS 3 a 5 . Folios que contienen

los comentarios críticos sobre la edición del Buscón.

Fuente: Biblioteca de la Real Academia de la Historia, M-RAH, 9/3649.

impresión habría necesitado unos 14 pliegos de 16 planas cada uno, para disponer de las 218 que ocupan texto y preliminares, por lo que el precio medio por ejemplar a la venta habría oscilado entre 42 y 56 maravedís; dado que en la época un real equivaldría a unos 34 maravedís ${ }^{18}$, el importe máximo por libro habría oscilado en torno a los dos reales. Los ocho abonados por el ejemplar del Buscón se antojan excesivos: reflejarían una demanda importante, derivada de la escasez de libros, y también un gran interés por parte de los posibles lectores. Datos compatibles con una auténtica novedad editorial, esperada con ansia debido a la talla literaria de su autor y la expectación suscitada por sus obras recientes; incompatibles, en cambio, con la eventual circulación profusa del relato picaresco ya en los años o incluso las décadas anteriores.

Como dato anecdótico, se apunta la satisfacción por la adquisición, «con los mayores afanes del mundo», y el hecho de que fue comprado a un religioso, un teatino (apelativo usualmente peyorativo, que designó a los primeros jesuitas).

A continuación, el remitente subraya la difusión pública y el éxito de «otras obras suyas», respecto a las cuales el Buscón se muestra mera reiteración, «lánguida [...] con poquísima gracia»: Quevedo carece de la frescura e ingenio de su juventud.

No le espere V. S. con el aplauso que han merescido otras obras suyas, porque es la cosa más lánguida que ha visto en su vida, porque se revuelca en todo lo que

${ }_{18}$ El real de cuenta, introducido en 1497, mantiene la paridad mencionada en el siglo XVI y en casi toda la primera mitad del XVII: experimenta cambios en 1642 (45 maravedís) y 1686 (64 maravedís). 
ha dicho antes en diferentes obrillas y con poquísima gracia: al fin, los ingenios tienen su puericia, adolescencia, juventud, virilidad y senectud; $y$ en este último paraje se hallan cuantos hoy conozco en Madrid, pues o no escriben o lo que escriben es sin aquella gracia primera.

A la altura de 1626, Quevedo está ya en la madurez, y los grandes autores barrocos de la generación anterior (Lope, Góngora) se encuentran cerca de su fin. Una vez más, la comparación con otras obras del escritor solo parece pertinente si el texto impreso resultaba entonces una estricta novedad.

La carta resume después el argumento, siguiendo el orden de los episodios, desde las aventuras en la venta de Viveros hasta las peripecias de Pablos como galán de monjas:

En él verá V. S. una casa de pupilaje pintada prolijísimamente y sin gracia, una estafa en la venta de Viveros pesada y sin sal, unas matracas en Alcalá asquerosísimas; traída por los cabellos y pesada, una introdución de un arbitrista, un diestro y un poeta, y la premática fría; una casa del verdugo de Segovia malísima, una introdución de un escudero forzada, y la vida dellos enfadosa de leer; un caballero fingido, un pobre, un comediante y un devoto de monjas.

El periplo abarca desde el capítulo 1, 3 hasta el 2, 9, de acuerdo con la distribución de las peripecias vitales de Pablos en dos libros en la princeps de 1626. Los detalles habrían sido ociosos, de haberse conocido con anterioridad la obra que acababa de imprimirse. Llama la atención el uso del artículo determinado en "la premática fría», en contraste con el indeterminado un y sus variantes flexivas usado en otros casos. Esta sería la única parte ya difundida previamente y conocida por el lector: en efecto, la Premática contra los poetas güeros, chirles y hebenes integrada en el Buscón $(2,3)$ registró una presumible circulación previa como obra independiente, animada por el auge de este tipo de textos burlescos en los primeros años del siglo XVII ${ }^{19}$.

La parte final de la carta, centrada en el Buscón, carece de datos que apunten hacia el momento de la escritura, si se exceptúa la fecha explícita que figura en medio del comentario: en un momento en que la comunicación epistolar parece a punto de cerrarse -con un año que parece 1626, pero podría ser 1625, como se ha comentado-, se reanuda de forma inesperada, aprovechando el retraso del correo por las inclemencias del tiempo; por este motivo, la datación de la carta no figura así al final, sino que queda desplazada en medio de la misma. Al dato mencionado se suman las abundantes alusiones a avatares históricos en los folios iniciales de la misiva, algunos de los cuales parecen apuntar al año de 1625 , por lo que han de tomarse también en consideración antes de inclinarse por una de las dos fechas posibles. La hipótesis más complicada, por contravenir un aserto crítico nunca puesto en tela de juicio, que el

19 De él es testimonio el manuscrito 9/764 de la Real Academia de la Historia (ff. 196-201). 
remitente hubiese escrito 1625 , lo que obligaría a despojar a la princeps de 1626 de su condición de tal; la más lógica y segura, por basarse en documentos y datos fehacientes, que ponga 1626, en cuyo caso habría que explicar por qué el final difiere de la princeps conocida, asunto del que me ocupo a continuación.

Ha de tenerse en cuenta también que todas las aprobaciones legales de la edición zaragozana de 1626, la considerada primera edición del Buscón, están datadas entre finales de abril y principios de mayo de ese año. Dicha edición estaba ya publicada «en el mes de julio» (Fernández-Guerra 1859, 667). Parece extraño que la noticia y los ejemplares de la impresión no hubiesen llegado a Madrid hasta el 9 de diciembre, si no es que el día y el mes se refieren al año anterior (1625) y a una edición diferente ${ }^{20}$. Debe admitirse, no obstante, que resulta improbable que una hipotética edición de 1625 no hubiese dejado huella alguna de su existencia.

La carta, fechada el 9 de diciembre y dirigida a un interlocutor noble que parece residir fuera de Madrid, se cierra con una irónica alusión al anuncio con que concluye el Buscón de Quevedo en la tradición manuscrita: «¡Y promete segunda parte del libro...!».

El Buscón se fue a las Indias, y no querría que desde allí nos lo trujese el auctor en la segunda parte, que sería peor que el pajarero del rey, que compuso aquí un libro mayor que el Flos Sanctorum del canto de los pajaros y ponía distintamente los pasajes de cada uno, y decía que el jilguero tenía un chirrí y dos chiculios; y el pardillo, dos cho cho, \&. ¡Y promete segunda parte del libro...!

Es cierto que la «segunda parte» que se reitera al final de la carta podría referirse al libro del «pajarero del rey» que se acaba de citar, pero parece más lógico suponer que siga hablando del Buscón, tras haber expresado el temor de que «nos lo trujese el auctor en la segunda parte»: por una parte, acaba de señalar la continuación del relato con un determinante $l a$, que indica que no se trata de una mera especulación del autor de la carta, en cuyo caso diría una, sino de una cita del pasaje final de la obra; por la otra, la nueva narración de Quevedo es (y parece seguir siéndolo) el tema central de la carta.

En las líneas precedentes, el remitente había relatado cómo acababa de adquirir uno de los cincuenta ejemplares de una edición zaragozana del texto picaresco llegados recientemente a Madrid, que en ese momento envía a un destinatario al que imagina deseoso de conocer el nuevo fruto del ingenio quevediano. Si llamativa resultaría la posible existencia de una impresión simultánea o incluso previa a la que se considera princeps de la obra, no es menos sorprendente la promesa

${ }^{20}$ También pudo circular por la Corte «la impresión furtiva con el mismo título, si bien disfrazada como si fuera la misma edición de Zaragoza» (Fernández-Guerra 1859, 667), promovida por el mercader de libros Alonso Pérez, en la imprenta madrileña de Alonso Martín. 
de una futura continuación: tal afirmación, tópica en obras del género picaresco como el Guzmán de Alfarache, no figura, precisamente, en la que la crítica identifica como primera impresión, la que salió de las prensas de Zaragoza en 1626, sino solo en tres testimonios manuscritos de época ${ }^{21}$, representantes de tres de las cuatro versiones variantes de la obra identificadas por Rey (2007c y 2014) ${ }^{22}$.

Además de la zaragozana de 1626, ese mismo año hubo otras tres ediciones: la de Barcelona, por Sebastián de Cormellas, presumiblemente contrahecha; la posible edición furtiva de Zaragoza contrahecha en Sevilla, en la imprenta de Francisco de Lira; y otra tal vez impresa en Madrid en la misma fecha, a cargo de la viuda de Alonso Martín, a costa de Alonso Pérez, mencionada por Castellanos $(1843,343)$. Esta última pudo estar inducida por la suspensión de la concesión de licencias para comedias y novelas, que animó a las imprentas de los reinos de Castilla a promover ediciones falsificadas, atribuidas a impresores de otros reinos, o contrahacer las obras nuevas que se editaban en los reinos castellanos, como explica Moll (1974), poniendo como ejemplo esta edición del Buscón ${ }^{23}$. Ya en 1627 se imprimió una en Valencia, por Crisóstomo Garriz; y en 1628, otra en Zaragoza, por Fernández de Heredia ${ }^{24}$. Las zaragozanas no mencionan la segunda parte; la de Barcelona de 1626, tampoco. Por tanto, ha de concluirse que el remitente de la carta podría estar citando otro impreso, que diferiría de la que llamamos princeps al menos en ese pasaje conclusivo de la obra.

Ambos datos combinados (la fecha no del todo clara y la promesa de segunda parte) sugerirían que podría haber existido y circulado una edición desconocida del Buscón, tal vez previa y de redacción coincidente con la tradición manuscrita y no con el impreso, en lo que atañe al final abierto del relato autobiográfico del pícaro Pablos. Incluso podría tratarse de alguna de las contrahechas que circularon por Castilla.

Pero aun es posible inferir nuevas conclusiones a partir de esta información del «aviso», ahora sobre el orden cronológico en que se habrían producido las reescrituras de la obra. Tobar $(2010,343-344 ; 2018,771)$ utilizó tal discrepancia, la presencia o ausencia de la promesa de una segunda parte ${ }^{25}$, para rebatir la sugerencia de Rey $(2007 \mathrm{c})^{26}$ sobre la posición de $Z$ en la historia textual, y

21 «Y fueme peor, como vuestra merced verá en la segunda parte» $(S B)$, «Y fue peor, como vuestra merced en la segunda parte verá» $(C)$; cito por la edición de las cuatro versiones de Rey (2007c).

22 «Y fueme peor» $(Z)$, se lee en la supuesta princeps de 1626, sin mención alguna a una posible segunda parte. «En todas las ediciones calcadas en la primera, falta», señala Astrana $(1932,125)$ a propósito de la referencia a la continuación.

23 Sobre todos los impresos mencionados, véase Rey (2007c, XLII-XLIII).

24 Remito a las descripciones de Rey (2007c, 340-342).

25 La relaciona con un epígrafe del manuscrito $B$ («Libro tercero y último de la primera parte de la vida del Buscón»).

26 Realizó un exhaustivo estudio de las variantes de las cuatro versiones, incluida la comentada. 
defender un orden inverso: su supuesta posterioridad respecto a $B$ y el resto de las fuentes manuscritas. La evidencia de que al menos una parte de la transmisión impresa del Buscón acogió la variante final que anunciaba la continuación del relato permite descartar la hipótesis defendida en solitario por Tobar, en el sentido de que su exclusividad en las fuentes manuscritas revelaría que el impreso es el que contiene la versión más tardía, la definitiva. Tobar concedió una importancia capital al dato, el cual -a su juicio- demostraría que Quevedo rectificó definitivamente, a través del texto impreso y para la posteridad, su inicial idea de un final abierto para el relato picaresco:

De nuevo, todo parece indicar que $B$ da cuenta de un momento creativo de Quevedo en el que, siguiendo el modelo de Alemán, contempló la idea de dar a su relato una continuación posterior; pero más tarde la descartó, y concluyó la historia de Pablos sin dejar un final abierto [...] Resulta más difícil imaginar que el proceso se hubiese desarrollado en sentido inverso (de $Z$ a $B$ )» (Tobar 2010, 343-344).

Varios indicios textuales sugieren que $Z$ es la última versión del Buscón [...] al final del relato no se alude - como en las tres fuentes manuscritas- a una futura segunda parte (Tobar 2018, 771).

Lo cierto es que tal variante no es privativa de las fuentes manuscritas, pues el final abierto conoció también una transmisión impresa, como lo demuestra el comentario de la carta de la RAH, basado en la lectura de un ejemplar del Buscón llegado a Madrid: al menos una de las ediciones divulgadas prometía una segunda parte, igual que los manuscritos. En lógica consecuencia, tal diferencia resulta inoperante a los efectos de postularla como prueba fehaciente de que el texto publicado representa la voluntad más tardía de su autor, expresada con una reescritura diseñada en exclusiva para la imprenta.

\section{Primer JUICIO CRÍtico CONSERVADO SOBRE EL BUSCóN}

Además de los datos anteriormente expuestos, la carta posee el interés adicional de ser un testimonio temprano de la recepción del relato picaresco. El documento se insertaría así, como texto pionero entre los conocidos, en el ambiente polémico que rodea a esta obra desde el mismo momento de su divulgación, que habría obligado a Quevedo a sucesivas reescrituras para sortear la censura, y que desencadenó la redacción de diversas invectivas especialmente injuriosas contra el relato picaresco: más brevemente, en la Venganza de la lengua española contra el autor del Cuento de Cuentos, bajo el pseudónimo de Juan Alonso Laureles (1629); y con mayor amplitud en el Memorial de Pacheco de Narváez (1630) y en la segunda «audiencia» de El tribunal de la justa venganza ${ }^{27}$,

27 Sobre estas diatribas escritas entre 1629 y 1635, véase Rey $(2014,20)$, quien las considera «las primeras interpretaciones del relato quevediano». Podría incluirse la carta aquí analizada como punto de arranque de tal labor crítica en torno al Buscón de Quevedo. 
publicada bajo autoría supuesta del «Licenciado Arnaldo Franco-Furt» $(1635)^{28}$. Referidas a otras obras quevedianas, pueden citarse también la censura del padre Pineda, las Anotaciones de Morovelli de la Puebla y una Respuesta anónima contra Política de Dios, divulgadas en los tres casos en 1626 ${ }^{29}$; y Excelencias y desagravios de los nobilísimos ojos de la cara, y zurriago contra el abogado del nefando ojo del culo, publicada bajo el pseudónimo «Bachiller Polvorín de TrasTe-Riego», tal vez de difusión previa a las mencionadas, tras la impresión de Gracias y desgracias del ojo del culo, texto hasta ahora desconocido y de reciente localización (Alonso Veloso 2017b).

A diferencia de las diatribas contra Quevedo que menudean en la cuarta década del siglo XVII, la carta posee un tono diferente, no polémico, y ajeno a los juicios morales y religiosos que tiñen las demás. Al tratarse de una carta privada, «familiar», estructurada a modo de «avisos», se presenta como opinión literaria, dirigida a un amigo, benefactor poderoso, a quien se desea advertir, para que la fama del autor del Buscón no le haga albergar falsas expectativas sobre el interés del libro que le envía.

La carta comienza con dos ideas esenciales, en un pasaje ya comentado: el Buscón es repetitivo en comparación con las «obrillas» anteriores de Quevedo (los breves textos burlescos que circularon previamente) y carece de agudeza: el escritor, con unos 45 años, se encuentra ya en la «senectud», incapaz de escribir «con aquella gracia primera». Al principio ofrece un mero resumen «urgente» del libro, pues su remitente va a mandar la carta enseguida; el retraso ulterior en el envío previsto le permitirá ahondar en su juicio sobre el Buscón: de modo apretado, enumera los diferentes avatares en la trayectoria vital de Pablos en orden cronológico, desde su estancia en la casa de pupilaje hasta el episodio de los galanes de monjas. Llaman la atención los adjetivos y adverbios empleados, peyorativos y enfáticos en lo que atañe a su prolijidad y al abuso de lo escatológico: «prolijísimamente y sin gracia», «pesada y sin sal», «asquerosísimas», «traída por los cabellos y pesada», «malísima», «forzada», «enfadosa de leer», «lánguida».

${ }^{28}$ Cabe la posibilidad de que el lugar de impresión (Valencia) y el impresor («Herederos de Felipe Mey»), en general todos los datos incluidos en la portada, sean falsos también. Véanse Alonso Veloso (2017a, 25-31) y Plata $(2019,87)$.

${ }^{29}$ Además del texto de Morovelli y la denuncia redactada por Juan de Pineda, perdida y conocida solo por la respuesta de Quevedo -Al padre Juan de Pineda, de la Compañía de Jesús, según el título que consta en el manuscrito no afectado por una posible censura (Alonso Veloso, 2020a y 2020b)-, debe añadirse ahora una invectiva de mayor calado, de reciente localización: la Respuesta al libro intitulado Política de Dios, gobierno de Cristo, tiranía de Satanás, manuscrita, de autor anónimo, fechada en octubre de 1626, y dirigida a Antonio de Sotomayor, confesor de Felipe IV y consejero real. El documento, hasta ahora desconocido, fue localizado por Alonso Veloso, quien da noticia del hallazgo (Alonso Veloso, en prensa a), estudia su impacto en la versión autorizada de Política de Dios (Alonso Veloso, en prensa b) y hace una edición crítica y anotada de la diatriba (Alonso Veloso, en prensa c). 
Sin una clara mención del género y sus rasgos, pero apelando al propósito satírico de Quevedo, el remitente de la carta apunta hacia la revista de tipos usual en la narrativa picaresca, aunque, una vez más, añora los tiempos pasados del escritor: «Que, siendo el fin de satirizar todos estos estados -en que él otras veces ha dicho maravillas-, en este libro dice maravillosas frialdades».

Tras apelar al juicio crítico de su destinatario noble, determinante para la valoración final que reciba el Buscón, en un ejercicio de captatio benevolentiae, apunta al desenlace de la obra: el remitente de la carta teme que la marcha del pícaro a las Indias dé lugar a un posible regreso, estrategia narrativa usual en el género para propiciar una continuación de la obra. Como se anticipaba, subraya, repitiéndolo en dos ocasiones, la promesa de la segunda parte del Buscón, que solo existe en la tradición textual manuscrita y no en la princeps que en teoría está comentando. Descalificación estética rotunda ante un libro presentado, en todo momento, como una estricta novedad.

Los ataques contra el Buscón se documentan desde 1628, en Valerio Vicencio, Al poema delírico:

\author{
Dejo los versos, las razones busco; \\ no hallo ni aun rebusco, \\ y admiro que razones \\ no halle el gran maestro de Buscones (vv. 25-28) \\ Aqueste es el legítimo sentido \\ del breve que has traído, \\ no el que dan tus razones; \\ no son los "breves" Sueños ni Buscones \\ para engañar el tiempo \\ con excusado ocioso pasatiempo (vv. 480-485)
}

Más allá de la descalificación de obras entonces muy recientes (el Buscón, 1626; Sueños y discursos, 1627) por su falta de provecho, no aparece aún el juicio moral ulterior, por supuesto atentado contra la ortodoxia católica, que en los años 30 busca la intervención de la Inquisición y la prohibición de las obras de Quevedo. El primer atisbo de tal estrategia se halla en la Venganza de la lengua española, de 1629:

No tiene la culpa toda el pobre caballero; mayor, sí, quien le dio licencia para imprimir en aquel otro libro, Buscón, de boberías, la devoción de la monja [...] Y da motivo al precipitado pueblo seglar a que imagine que aquellos devaneos, libertades y variedades que pinta son comunes, y que con aprobación se hacen, pues con licencia se imprimen (p. 1042)

De forma más explícita, Luis Pacheco de Narváez examina el Buscón, entre otras obras, añadiendo a las «deshonestidades, palabras obscenas, torpes y asquerosas» sugeridas por la carta consideraciones de mayor calado, en el 
Memorial denunciando al tribunal de la Inquisición cuatro libros de don Francisco de Quevedo, de 1630: la mezcla irreverente de lo divino y lo humano (p. 1046). Su tránsito por una veintena de pasajes del relato desemboca en el que cerraba la crítica de la misiva, el de los galanes de monjas, con una síntesis contundente: «este libro [...] lo tengo por un seminario de vicios y un maestro que enseña cómo se han de cometer los pecados» (p. 1048).

También el autor de El tribunal de la justa venganza, bajo el seudónimo de «Licenciado Arnaldo Franco-Furt», obra publicada en 1635, desgrana en la segunda audiencia 23 cargos «contra el libro Buscón», que, señala, «primeramente fue impreso en la ciudad de Zaragoza» (p. 60); el cierre de los mismos es, una vez más, el episodio de los devotos de monjas, donde Quevedo «las trata peor que si fueran públicas rameras» (p. 82) ${ }^{30}$.

No hay en ninguna de las invectivas comentadas la menor referencia a la posible continuación del relato, la segunda parte que menciona el autor de la carta; el Memorial y El tribunal citan explícitamente las ediciones de Barcelona y Zaragoza, que no contienen ese final: tienen delante impresos diferentes del aludido en la carta. De no haber sido así, habrían atacado la promesa quevediana de un segundo Buscón para impedir su futura divulgación impresa. Como todas las ediciones derivadas de la de Zaragoza de 1626 omiten tal indicación, podría postularse que esos ejemplares cuya llegada a Madrid anuncia el cortesano son indicio de otra edición hoy desconocida.

\section{Conclusiones}

La carta conservada en la Real Academia de la Historia, además de ser valiosa como crónica «periodística» del momento, la década de los años 20 del siglo XVII, también posee un interés literario particular a propósito de la fecha de redacción, la posible difusión manuscrita temprana y la recepción del Buscón de Quevedo. El análisis de la misiva, que da noticia sobre la reciente impresión del relato picaresco y evidencia la decepción del emisor ante un texto literario que juzga de inferior calidad respecto a anteriores obras burlescas quevedianas, permite proponer las siguientes conclusiones:

6.1. Cuando el Buscón llega a la imprenta mediada la década de 1620, y los ejemplares del libro son recibidos en Madrid, la obra de Quevedo aún no era conocida en el ámbito de la Corte: los datos apuntados demuestran su novedad y permiten inferir que no existió una profusa difusión manuscrita previa como se suponía.

30 Sobre esta invectiva y su ataque contra el Buscón, en relación con la datación de la obra, puede consultarse Cabo (2011, 34). Cito la obra por la edición de Roncero (2008). 
6.2. La que hoy consideramos princeps del Buscón puede no haber sido la primera o, al menos, pudo convivir con otra edición impresa en la misma ciudad y hoy desconocida, si es que no fue falseado el lugar de impresión, habida cuenta de la prohibición de imprimir novelas en Castilla vigente en esas fechas. Tal edición habría incluido la promesa final de una segunda parte, como sucede en los tres manuscritos conocidos, y a diferencia de la que consideramos primera edición.

6.3. La referencia al anuncio de la segunda parte del relato picaresco comentado en el «aviso»-que ahora sabemos se incluyó también al menos en algún impreso difundido en coincidencia con el zaragozano- obliga a desechar la idea de que esta variante es privativa de las fuentes manuscritas, al tiempo que invalida la hipótesis de que tal divergencia sea indicio de que la versión más tardía de la obra fue la publicada: según la propuesta ahora en entredicho, el hecho de haberse impreso explicaría que su texto albergase una exclusiva rectificación de Quevedo que plasmaría su última voluntad sobre el Buscón, la definitiva, consistente en evitar un final abierto para su relato. Ahora sabemos que el tipo de cauce, manuscrito o impreso, resultó indiferente para elegir el cierre de la obra.

6.4. La variante en la conclusión de la obra no prueba fehacientemente la existencia de un impreso del Buscón previo a la princeps de 1626. Pero los comentarios del remitente de la carta demuestran que tuvo a la vista una edición que hubo de publicarse y difundirse de modo más o menos simultáneo a la primera edición.

6.5. La carta está fechada en 1626, año más probable, pero el trazo poco nítido del último número también podría ser un 5 . La fecha hipotética de 1625, mera especulación que tal vez nunca llegue a confirmarse, concuerda con algunas referencias históricas incluidas en la primera parte de la carta: en particular, las noticias sobre los éxitos de Spinola en los Países Bajos y la ocupación de la Valtelina por los franceses. No obstante, aún carecemos de datos consistentes, en particular la conservación de algún ejemplar de la edición aludida, para sugerir que el Buscón podría haber sido impreso por vez primera en 1625 y no en 1626.

6.6. La carta, concebida a modo de «aviso», es el primer juicio crítico sobre el Buscón y, tomando en consideración los comentarios tan negativos que desgrana sobre el ingenio de Quevedo, cabría postularla como antecedente indirecto de las invectivas contra la obra que proliferaron en torno a los años 30 del siglo XVII.

\section{TRANSCRIPCIÓN Y ANOTACIÓN DEL TEXTO}

El objetivo de recuperar el contenido de la carta custodiada en la Academia de la Historia implica ofrecer la transcripción completa de su texto, moderni- 
zado en ortografía y puntuación, así como una anotación a pie de página, útil en la medida en que permite fijar por aproximación la fecha del escrito, anclado en avatares históricos bien conocidos. Dado que la referencia al Buscón, en dos folios, forma parte de una carta más amplia, escrita con idéntica caligrafía $\mathrm{y}$ tinta por el mismo remitente, y dirigida a un mismo destinatario, sin separación alguna respecto a los dos folios iniciales del manuscrito, se opta por transcribirla en su integridad. El contenido del comienzo no se atiene estrictamente a Quevedo y su relato picaresco, aunque sí al contexto de su recepción; transita desde cuestiones sociales relacionadas con matrimonios proyectados, para pasar a un jugoso repaso de personajes y circunstancias que podemos considerar de carácter político, en muchos casos relacionados con el papel de España en el conflictivo escenario europeo de la época, de indudable interés: más allá de la información que aporta sobre la nobleza y los movimientos cortesanos, evidencia la usual intersección o superposición de los campos literario y de poder, descrita por Gutiérrez (2005) a propósito de las primeras décadas del siglo XVII y la figura de Quevedo en la vida de la Corte madrileña. Y aporta datos relevantes para la datación de la carta y la esperada llegada del Buscón a Madrid.

\section{[Avisos de Madrid de 1626] $]^{31}$}

Vuelvo a inviar a V. S. el agradescimiento que me invía por la cortesía de la terciana ${ }^{32}$, porque ha vuelto con mayores bríos que antes. Dios lo remedie, y guarde a V. S. por los favores y mercedes que me hace con su carta de los 2 deste $^{33}$.

No hacía embarazo ninguno a mi S. S. ${ }^{34}$ para su casamiento la dureza de la condición del padre ${ }^{35}$, que el mirar la subcesión tan vecina ${ }^{36}$ hacía dulce

31 [Avisos de Madrid de 1626]: reproduzco el título incluido en la catalogación, que no se encuentra en la carta manuscrita. Mantengo la estructura de párrafos del original, porque evoca los distintos temas, «avisos» sobre los que va discurriendo el remitente.

32 terciana: fiebre palúdica de carácter epidémico en el siglo XVII, sufrida por personajes históricos tan importantes como Felipe IV o el pintor Diego Velázquez.

33 Vuelvo a inviar [...] de los 2 déste: 'le devuelvo el agradecimiento que me hace llegar, aprovechando la remisión de la terciana, porque ha vuelto con más intensidad; deseo que Dios remedie ese padecimiento y le guarde...'.

$34 \mathrm{miS} . \mathrm{S}^{a}$ en la carta figuran dos abreviaturas de tratamiento: la más repetida, «V. S.» ('vuestra señoría'), dirigida al destinatario; y S. S. ${ }^{a}$ (o S. ${ }^{a}$ ), en este párrafo, referida a la mujer noble de quien habla.

35 la condición del padre: aunque es evidente que se trata de un noble, «lo mejor despaña», con hacienda, no he podido identificar de quién se trata de modo concluyente, ni tampoco apuntar el nombre de esa hija casadera, viuda por partida doble y sufridora de la «dureza» paterna.

${ }^{36}$ la subcesión tan vecina: antes de la desaparición del padre, cualquier pretendiente habría sorteado el obstáculo de su mal carácter, con la expectativa de que la hija lo «suce- 
cualquiera inconviniente, pero hoy sin duda es lo mejor despaña, no tanto por la hacienda -que es muy buena- como por las grandes partes que tiene de valor y prudencia, espirimentadas en el desastre ${ }^{37}$ de la pérdida de dos maridos y en la suavidad de haber sabido llevar la condición del padre. Heredé yo en la voluntad de su S. S. ${ }^{a}$ mejorada la merced que me hacía mi amo, que era mucha, y ansí asisto aquí a mis pretensiones con toda la comodidad que puede tener un hombre de mi esfera. En vida del padre hubo infinitísimos casamientos, y los que hay al presente carecen de número; y nada hay en este mundo en que su S. ${ }^{a}$ piense menos.

Paso de casamientos a Flandes, que las cosas de allá están de lindo semblante, con las dos veces que Espinola rechazó en el País de Bax $^{38}$ al enemigo, y con la rota ${ }^{39}$ que le dio el conde Enrique ${ }^{40}$, con que se abren aquellos diques ${ }^{41}$ a toda priesa; y ahora que supo que había venido desaparejada la armadilla que salió de Inglaterra y con almiranta ${ }^{42}$ y otros dos bajeles menos, se fue luego ${ }^{43}$ el Marqués ${ }^{44}$ a Dunquerque y estaba a toda priesa armando 28 bajeles que, a la hora de ahora, habrán hecho buenos daños ${ }^{45}$.

dería» enseguida en el linaje, dada la inmediatez de su muerte. Ya desaparecido, la mujer es ya uno de los mejores partidos «de España».

37 desastre: tengo dudas en la transcripción de este sustantivo, que deduzco atendiendo al posible sentido en el contexto, pues no soy capaz de entender con nitidez los trazos de esta palabra, situada al final de una línea.

${ }_{38}$ País de Bax: 'los Países Bajos', en posible evocación de la denominación francesa «Pais-Bax».

39 rota: «Rompimiento del ejército o tropa contraria, desbaratándola en batalla y deshaciéndola» (Autoridades).

40 conde Enrique: se refiere a uno de los generales de Spinola, el conde Enrique de Bergh, quien tomó el mando en Flandes en sustitución de Spinola posteriormente, cuando fue trasladado a Italia en 1629; fue evocado por Calderón en el personaje del conde Enrique de Vergas, en la comedia El sitio de Bredá.

${ }^{41}$ aquellos diques: los que protegían las tierras ganadas al mar en los Países Bajos. Una de las estrategias aplicadas para conseguir la rendición de Breda consistió en anegar todos los diques de acceso a la ciudad hasta colapsarla.

42 almiranta: «Nombre distintivo del navío donde se embarca y navega el almirante general de la armada naval. Este navío, cuando navega o pelea, ocupa el puesto de la retaguardia, cerrando y recogiendo toda la armada, o escuadra» (Autoridades).

${ }^{43}$ luego: 'enseguida'.

44 el Marqués: Ambrosio Spinola, Marqués de los Balbases, fue capitán general de la Armada de Flandes desde 1622 hasta 1630. En 1624 inició el asedio de Breda, que culminó con su rendición en junio de 1625. «El 15 de junio llega noticia de la rendición de Bredá por Spinola», señala Jauralde $(1999,503)$.

45 y ahora que supo [...] buenos daños: Stradling (2003, 43-44) sintetiza los hechos aludidos en la carta, que podrían remitir al año 1625: "Though the armada itself had not yet achieved a major operational success, glory was not long delayed, for during 1625 -that unprecedented year of military success for the Spanish Monarchy- it was able to contribute in significant fashion [...] The work seemed to have been wasted, however, when England 
Hase callado nuevo ${ }^{46}$ la voz ${ }^{47}$ de que daban a Zapata la Inquisición Gene$\mathrm{ral}^{48}$, que ${ }^{49}$ aquel fervor con que al principio corrió fue fundado en que la había pedido para él el Cardenal Infante ${ }^{50}$, que son medios tan flacos como otros, y está corridísimo ${ }^{51}$ de lo que ha hecho.

declared war on Spain in April 1625. It became known that a joint Anglo-Dutch expedition was being gathered, with an attack on the Spanish mainland as its priority. The Archdichess Isabel joined Spínola in Dunkirk, where (following the fall of Breda in July), the captain-general had set up his headquarters. The demands of the expeditionary force obliged the Dutch to reduce their blockading squadron to eighteen warships. But this seemed irrelevant, since the Flanders armada dared not move with the allied fleet possibly at sea [...] English commitment and losses -especially in terms of vessels engaged- were greater than her ally's by a proportion of at least four to one. Spanish sources suggest that in November and December 1625, only around fifty of the English contingent were able to regain their home bases. The English defeat [...] was on a comparable scale to the worst disasters of contemporary Spain».

46 nuevo: 'de nuevo'.

47 la voz: 'el rumor'.

48 daban a Zapata la Inquisición General: Antonio Zapata y Cisneros (1550-1635), sobrino nieto del cardenal Cisneros, fue obispo de Cádiz y Pamplona, arzobispo de Burgos y cardenal, consejero de estado de Felipe III y virrey de Nápoles entre 1620 y 1622, además de inquisidor general. Tras regresar a España desde Italia, asumió la administración del arzobispado de Toledo en 1625, durante la minoría de edad del arzobispo titular, el cardenal infante Fernando de Austria. Alcanzó el cargo de inquisidor general del reino en enero de 1627, a través de una bula otorgada por el papa Urbano VIII. Sobre la sustitución del anterior inquisidor general, Andrés de Pacheco, fallecido en 1626, y las complicadas relaciones de Quevedo con Zapata, remito a Jauralde $(1999,513)$.

49 que: con valor causal.

50 el Cardenal Infante: se refiere a don Fernando de Austria (1609 ó 1610-1641), quien fue infante de España y Portugal, gobernador del Estado de Milán y los Países Bajos españoles, virrey de Cataluña, administrador apostólico de la Archidiócesis de Toledo y comandante en la Guerra de los Treinta Años. Hijo del rey Felipe III y la reina Margarita de Austria, fue nombrado arzobispo de Toledo en 1619 y cardenal poco tiempo después; fue Antonio Zapata quien le impuso el capelo cardenalicio (véase Aldea 1997, 35-36). Olivares expresó sus ideas sobre el estado del infante Fernando, a quien destinaba al papado, en carta de 1625 dirigida a Felipe IV, en un memorial de 1627 y en el «Gran Memorial» de 1624 (Elliott y De la Peña 1978: I, 169-170, 215-228 y 52-53, respectivamente).

${ }^{51}$ corridisimo: el Cardenal está 'avergonzadísimo' de haber pedido que se nombrase inquisidor general a Zapata; solo su apoyo a la concesión de tal distinción justificó el fervor inicial que generó la propuesta, ya olvidado. Sobre la trama urdida en la Corte en esta época, con la aquiescencia de Olivares y petición explícita de Felipe IV, para sustituir a Zapata por el Cardenal Infante, hermano del monarca español, en el cargo como inquisidor general, auxiliado por el Cardenal Borja como administrador, puede consultarse Puyol (1993, 245246). El papa Urbano VIII denegó tal propuesta, y Zapata cesó finalmente como Inquisidor General en 1632. 
Chinchón ${ }^{52}$ irá sin falta ninguna al Pirú y, si hay quien se lo diga, lo ha de jugar $^{53}$. Ya dije a V. S. que había venido $\operatorname{Lemos}^{54}$ a la vista de un pleito que tiene con Monterrey ${ }^{55}$; hanle dado 20.000 ducados $^{56}$ de ayuda de $\operatorname{costa}^{57}$, y yo digo que le deben de querer condenar.

${ }^{52}$ Chinchón: Luis Jerónimo de Cabrera y Bobadilla (1589-1647), cuarto conde de Chinchón, fue tesorero general del Consejo de Aragón entre 1612 y 1627, y virrey del Perú de 1629 a 1639. Al terminar su mandato como virrey, en 1639, regresó a España, donde fue consejero de estado; acompañó a Felipe IV en la campaña de Navarra, Aragón y Valencia. Según González Dávila $(1623,455)$, tenía «en el Consejo el primer lugar y voto después del Presidente, por gracia particular del Rey».

${ }^{53}$ jugar: «Se toma también por intervenir o tener parte en la disposición de algún negocio» (Autoridades). Parece sugerirse que Chinchón aceptará de buen grado la marcha a Perú si se lo proponen: fue virrey allí a partir de 1629.

${ }^{54}$ Lemos: no puede ser Pedro Fernández de Castro y Andrade, VII Conde de Lemos («Gran Conde de Lemos»), muerto en 1622; sobre sus movimientos ante el inminente cambio de monarca y su rivalidad con Uceda, en el contexto previo a la caída de Lerma, Elliott (1990, 58-60). Podría referirse a su sucesor, Francisco Ruiz de Castro (1582-1637), virrey de Nápoles, que renunció a sus títulos y se hizo monje.

55 Monterrey: Manuel Alonso de Zúñiga Acevedo y Fonseca (1586-1653), VI Conde de Monterrey, fue comendador de la Orden de Santiago, condestable de Castilla, presidente del Consejo de Italia y miembro del Consejo de Estado de Felipe IV, así como presidente de las Cortes de Aragón, embajador ante la Santa Sede, virrey del reino de Nápoles y teniente general de los ejércitos en la guerra con Portugal. Su esposa, Leonor María de Guzmán y Pimentel, era hermana del válido del rey Felipe IV, Gaspar de Guzmán y Pimentel, III conde de Olivares, I duque de Sanlúcar, quien estaba casado con Inés de Zúñiga y Velasco, hermana de Manuel y dama de la reina Margarita. Después de un conflicto relacionado con la herencia de su padre, que había sido virrey del Perú, la intervención de su tío Baltasar y su primo hermano, el conde-duque de Olivares, ayudó a solventar sus problemas. El VI Conde de Monterrey sostuvo un largo pleito (1609-1628) con los condes de Lemos sobre los bienes de la casa de Biedma y de Ulloa. Aún a la altura de 1627 continuaban los antiguos pleitos entre la casa de Monterrey y la de Lemos, pues se celebró un juicio «sobre ciertos lugares que rentavan seismil ducados; poseyalos Monterrey. Y se sentenció de manera que ambos quedaron quejosos. Y salieron del Consejo a las 10 de la noche» ( $A H N$, Consejos, libro 635, f. 476 r.; citado por Rivas $(2015,225)$.

5620.000 ducados: interpreto así la abreviatura 20U.

57 ayuda de costa: «Es el socorro que se da en dinero, además del salario o estipendio determinado, a la persona que ejerce algún empleo; y también se llama así cuando se da a otra cualquier persona sin esta circunstancia» (Autoridades). 
El obispo de Oviedo ${ }^{58}$ será arzobispo de Sanctiago ${ }^{59}$ y presidente de Castilla, dicen que por un año, y es para probar el sujeto ${ }^{60}$ y sin duda ninguna es cuando se hacen mayores yerros, que acá no se tiene noticia de aquellas razones divinas de Marco Antonio Colona ${ }^{61}$, cuando fue a gobernar a Sicilia, que, viniendo los del patrimonio a visitalle en forma de tribunal, les dijo «este año gobernarán Vmds.; el que viene, yo y Vmds.; y el tercero yo solo» ${ }^{62}$, aunque yo entiendo que el primero y todos cuantos estuviere ha de dar satisfación este sujeto.

Al fin, Señor, todos los entendidos y los que parecen briosos hacen mayores gazafatones ${ }^{63}$, y es sin duda que nadie da paso sin desinio, desde el independente hasta el menor: ya oyó V. S. que antes de la jornada de Aragón ${ }^{64}$ besó

58 El obispo de Oviedo: es posible que se refiera a Juan de Torres Osorio (1562-1633), religioso español que ocupó las sillas episcopales de Siracusa y Catania en Italia, y Oviedo y Valladolid en España; también fue nombrado obispo de Zaragoza, arzobispo de Monreal y obispo de Málaga, aunque no ejerció como tal. Felipe III lo nombró juez del reino de Sicilia, y rechazó el obispado de Zaragoza y el arzobispado de Monreal. En 1613 fue promovido para la diócesis de Siracusa, que asumió ese año. En 1619 fue nombrado obispo de Catania, cargo que ejerció hasta 1624, cuando fue nombrado obispo de Oviedo, obispado cuya toma de posesión se produjo al año siguiente; dos años después, fue trasladado al obispado de Valladolid, pero no asumió tal nombramiento hasta 1629, debido a que Felipe IV lo designó visitador de la Real Chancillería de Granada.

59 arzobispo de Sanctiago: entre los años 1624 y 1626, ejerció tal dignidad eclesiástica Agustín Antolínez, cuyo sucesor fue José González Villalobos, entre 1627 y 1630.

60 el sujeto: 'el tema', aquí 'el cargo'.

${ }^{61}$ Marco Antonio Colona: Colonna (1535-1584) fue nombrado virrey de Sicilia por el rey de España, Felipe II, en 1577. Después de salir victorioso en la batalla de Lepanto, en 1571, regresó a Roma, y el nuevo Papa Gregorio XIII lo ratificó en su puesto de capitán general, encomendándole la lucha contra los turcos en favor de la Tierra Santa. Desde que asumió el cargo de virrey en Sicilia, Colonna y los inquisidores mantuvieron un conflicto permanente en torno a los ámbitos de influencia de ambas jurisdicciones, problema al que parece aludir la carta. Hasta tal punto que el Consejo de Italia reclama la intervención del rey en 1578: «Felipe II, ante la gravedad de la situación, ordenó la formación de una Junta con dos miembros de cada consejo, con el fin de que elaboraran una Concordia, un documento legal que fijase los marcos privativos de cada autoridad» (Rivero 1993, 77). Sobre este asunto, véanse Pizarro (2004, 337-338) y Rivero (1993, 73-101).

${ }^{62}$ viniendo los del patrimonio [...] y el tercero yo solo: no he localizado la cita con las palabras atribuidas a Colonna. Sobre los interrogatorios de la visita de Gregorio Bravo a Sicilia en 1583, para investigar la gestión de Colonna y su posible influencia en su caída, así como sobre el tribunal de patrimonio, en relación con el papel del virrey, puede consultarse Rivero (1993, 82), quien concluye: «Los miembros del Tribunal del Patrimonio contrabandeaban con tal impunidad y de una forma tan poco oculta que se pensó que se habian cohechado tribunal y virrey en estos negocios. A través de las conclusiones extraídas posteriormente en la Visita, se comprobaron multitud de casos similares a estos, de parecida o igual gravedad, que eran de dominio público en la isla»; véanse también las pp. 90-98.

${ }^{63}$ gazafatón: «Disparate, bobería, sin pies ni cabeza. Otros dicen gazapatón» (Autoridades).

${ }^{64}$ antes de la jornada de Aragón: a finales de 1625 se decide la convocatoria de Cortes en Aragón, Valencia y Cataluña para la aprobación de nuevas medidas económicas; a principios 
Lerma $^{65}$ la mano por no sé qué merced, que nunca había salido a luz, hasta que él ha hecho presente de una hija única que tiene al Conde de Olivares, para que disponga della a su gusto; y la casa con don Hernando de Guzmán, en cuya cabeza y casa pone todos los acrecentamientos de los mayorazgos y los que adelante hará6 ${ }^{6}$. Y ha sacado Lerma cuarenta mil ducados de ayuda de costa, y aun dicen que le harán mayordomo mayor ${ }^{67} ; \mathrm{y}$ los Carpios, con sus andaluzadas y bravatas, me parece que quedan destituidos de todo favor y esperanzas, y habrán de tomar resulución de volverse a Adamuz a desjarretar jabalíes ${ }^{68}$. Y

de 1626 tuvo lugar la célebre «jornada de Aragón», que Felipe IV emprendió para conseguir el apoyo de las Cortes en Barbastro. Este proyecto, enmarcado en la Unión de Armas de los reinos peninsulares, forzada por Olivares, llevó a la Corona a exigir a cada territorio una contribución de soldados proporcional a su población; los resultados no fueron los esperados, e incluso las Cortes de Cataluña se negaron. Véanse dos cartas de Olivares sobre este asunto, datadas en 1625 y 1626, la última desde Monzón (Elliott y De la Peña 1978: I, 173-197). El propio Quevedo asistió con el rey, y en Zaragoza se sucedieron las impresiones de Política de Dios, el Buscón y los Sueños; véase Astrana (1946, XIII). Acerca de la influencia cortesana de Quevedo en torno a 1625 y su participación en el viaje real a Aragón y Cataluña, Jauralde (1999, 501), quien ofrece información sobre el desarrollo de ambas jornadas (pp. 503-509).

${ }^{65}$ besó Lerma: por las fechas no puede referirse al Duque de Lerma que fue poderoso valido de Felipe III, pues murió en mayo de 1625; debe de aludir a Francisco Gómez de Sandoval Manrique de Padilla, segundo Duque de Lerma (m. 1635), Adelantado de Castilla.

${ }^{66}$ Conde de Olivares [...] los que adelante hará: el linaje de los Guzmán tiene varias ramas emparentadas, con mayorazgos nobiliarios en Andalucía y en Castilla: las casas de Medina Sidonia y de Olivares, por ejemplo, entre los primeros; o los marqueses de Toral y los condes de Orgaz entre los segundos. Entre los personajes históricos más conocidos del linaje se cuentan Guzmán el Bueno, el VII duque de Medina Sidonia o el propio conde-duque de Olivares. A propósito de sus relaciones con los Lerma, cabe recordar que Manuel Alonso Pérez de Guzmán el Bueno (1579-1636; XIII señor de Sanlúcar, XI conde de Niebla, VIII duque de Medina Sidonia y VI marqués de Cazaza) se casó en 1598 con Juana Gómez de Sandoval y Rojas y de la Cerda, hija del I duque de Lerma, valido de Felipe III; en 1625, dirigió la operación militar que rechazó el ataque de la flota anglo-holandesa a Cádiz.

67 mayordomo mayor: uno de los tres oficios de mayor rango en la Casa Real: «jefe de la Casa y Cámara, era responsable de la alimentación y el alojamiento del soberano, pero, además, le acompañaba [...] cuando salía de Palacio, regulaba las audiencias con personalidades estatales [...] encauzaba las peticiones de justicia o de gracias y mercedes, vigilaba la seguridad, custodiaba de noche las llaves palaciegas y recibía el juramento de los criados. Su misión se consideraba tan importante en la Corte que gozó de señalados privilegios» (Enciso 2005, 97). Entre 1621 y 1624 ejerció ese cargo Juan Hurtado de Mendoza, duque del Infantado; de 1629 a 1639, le correspondió a Antonio Álvarez de Toledo y Beaumont, duque de Alba.

${ }^{68}$ y los Carpios [...] a desjarretar jabalies: los Carpios fueron señores de Adamuz, villa que pertenecía al Marquesado de El Carpio. Luis Méndez de Haro y Guzmán, VI marqués del Carpio, I duque de Montoro y II conde-duque de Olivares (1598-1661), era sobrino del conde-duque de Olivares, a quien sucedió como valido de Felipe IV tras su caída en 1643, y con quien fue su Caballerizo mayor desde 1648. Es posible que en este fragmento se evoque la visita realizada por Felipe IV a Adamuz en 1624, en una comitiva integrada por Olivares, entre otros, y recibida por el Marqués del Carpio; Felipe IV estuvo alojado en el castillo de 
con todas estas cosas está muy en su punto la santidad del conde ${ }^{69}$ y hay públicas alabanzas della $[\ldots]^{70}$

Don Diego Mesía ${ }^{71}$ me aseguran que se casará con su hija del de la Hinojosa $^{72}$, después que a don Hernando le ha cabido tan gran dicha ${ }^{73}$.

los marqueses del Carpio durante su viaje por tierras andaluzas. Los detalles de tal visita se narran en la relación de Páez de Valenzuela (1624). El hecho fue recreado literariamente por Vélez de Guevara en El diablo cojuelo, tranco VI: «En este tiempo, nuestros caminantes, tragando leguas de aire, como si fueran camaleones de alquiler, habían pasado a Adamuz, del gran Marqués del Carpio Haro y nobilísimo descendiente de los señores antiguos de Vizcaya, y padre ilustrísimo del mayor Mecenas que los antiguos ingenios y modernos han tenido, y caballero que igualó con sus generosas partes su modestia» $(2007,126)$. Un poco más adelante, comenta la burla de Quevedo contra Pacheco de Narváez en el Buscón.

69 la santidad del conde: parece referirse al conde-duque de Olivares, que consigue el favor del futuro Felipe IV, quien le nombró su favorito cuando llegó al trono en 1621, en lugar del duque de Uceda; ese mismo año alcanzó el título de grande de España, y asumió funciones de valido en 1622. Desde ese momento, fue sumiller de Corps y caballerizo mayor, y camarero mayor desde 1636; fue también comendador mayor de la Orden de Alcántara, alcaide de los Reales Alcázares de Sevilla, gran canciller de las Indias, general de la Caballería española, tesorero general de la Corona de Aragón y teniente general, además de ocupar asiento en las Cortes de Castilla. El III Conde de Olivares empezó a llamarse conde-duque de Olivares desde que Felipe IV le concedió el ducado de Sanlúcar, en 1625. Para esta figura, véase particularmente uno de los abundantes estudios de Elliott (1990); el propio Olivares resume las mercedes obtenidas del monarca en el «Memorial genealógico», de 26 de julio de 1625 (Elliott y De la Peña 1978, I: 147).

${ }^{70}$ alabanzas della: el resto del párrafo, una línea y media, parece censurado, con trazos superpuestos en tinta más oscura, que hacen el texto ilegible.

${ }^{71}$ Don Diego Mesía: Diego Mexía de Guzmán y Dávila (ca. 1580-1655), vizconde de Butarque y primer marqués de Leganés, fue político y militar, y luchó desde 1600 en los Países Bajos, donde estuvo durante más de veinte años como oficial y gentilhombre de cámara del archiduque Alberto de Austria. En 1621, tras la muerte de éste, regresó a Madrid y se convirtió en persona influyente gracias al apoyo de su primo, el conde-duque de Olivares, valido de Felipe IV. Acompañó al rey y a Olivares en su viaje a la Corona de Aragón, y en julio de 1626 fue nombrado miembro del Consejo de Estado; en 1627 asumió el marquesado de Leganés, y ese mismo año se casó con una dama de honor de la reina Isabel de Borbón, Polixena Spinola, hija de Ambrosio Spinola. Especialista en los Países Bajos, consiguió que participasen en la Unión de Armas en 1627. Fue nombrado presidente del Consejo Supremo de Flandes y Borgoña, y previamente, en 1626, general de caballería del ejército de Flandes. Como otros personajes citados en la carta, formó parte de la Junta de las Cortes de Aragón, integrada por nobles muy próximos a Olivares: el marqués de Heliche, el de la Hinojosa, Diego Mexía, el conde de Chinchón y el protonotario Jerónimo de Villanueva.

${ }^{72}$ Hinojosa: Juan de Mendoza y Velasco (muerto en 1628), noble, militar, diplomático y hombre de estado español, fue I marqués de San Germán y de la Hinojosa, caballero de la Orden de Santiago, gentilhombre de cámara de Felipe III y su consejero de estado, gobernador del Milanesado y virrey de Navarra; actuó como embajador de Felipe IV en Inglaterra y fue presidente del Consejo de Indias.

73 después que a don Hernando le ha cabido tan gran dicha: la de casarse con la hija de Lerma, por directa concesión de Olivares. 
El arbitrio del amigo sea rescibido por el mejor de todos en todas las juntas, y andan poniéndolo en ejecución, y porque él se halla en todas ellas. No me ha podido traer el papel, porque tiene 18 pliegos.

Días ha que no hay cartas de Italia, ni se sabe de allá nada, sólo que los franceses no quieren dejar la Valtelina, ni Saboya viene en lo tratado acá ${ }^{74}$.

Este lugar está lleno de unos entendidos de corteza sola y superficie ${ }^{75}$, y estoy con uno destos tan enojado que me diera de puñaladas con él, porque, no habiendo venido desde Zaragoza ${ }^{76}$ más de 50 libros impresos ${ }^{77}$-el título, la Historia de la vida del Buscón ${ }^{78}$; el autor, don Francisco de Quevedo; el asump-

74 los franceses no quieren dejar la Valtelina, ni Saboya viene en lo tratado acá: en el contexto de la guerra de los Treinta Años, el control del valle de la Valtelina, región militarmente estratégica como vía de comunicación para los tercios españoles entre el norte de Italia y los Países Bajos y Alemania, desató la guerra de la Valtelina (1621-1639). España, que dominaba el vecino ducado de Milán, se alió con las repúblicas de Génova y Lucca, así como los ducados de Parma, Módena y Toscana, enfrentándose contra la formada por Francia con el cantón suizo de los Grisones (bajo cuyo gobierno se encontraba la Valtelina), el ducado de Saboya y la república de Venecia. En el año 1625, Francia ocupa el paso de la Valtelina, y para ello se alía con Venecia y Saboya en contra de Génova, aliado tradicional de España; no será hasta 1626 cuando España acabe con el bloqueo de Génova y restablezca el statu quo en lo que atañe al paso de la Valtelina, con el «Tratado de Monzón». Véase Castilla y Rodríguez (2011, 231). Como recuerda Rivas $(2015,221-222)$, Urbano VIII designó a su sobrino, el cardenal Francesco Barberini, para negociar un posible acuerdo entre Francia y España ante el conflicto de la Valtelina; permaneció en París entre marzo y diciembre de 1625, no consiguió avances y viajó a España con el mismo fin: a su llegada a Barcelona, el 5 de marzo de 1626, acababa de producirse en Monzón la firma del tratado que pensaba promover, con intervención de Felipe IV y un representante francés. Sobre el tratado, puede consultarse una relación de la BNE (con signatura Mss. 2358, ff. 140-143 v); véanse también la edición del tratado de Ochoa Brun (2006) y el análisis de Aldea Vaquero (1986).

75 entendidos de corteza sola y superficie: 'entendidos superficiales', aquí sobre materias literarias.

${ }^{76}$ desde Zaragoza: el autor del «aviso» escribe desde Madrid, donde llegan ejemplares desde Zaragoza.

77 más de 50 libros impresos: sobre la actividad de los libreros y la imprenta en España en el Siglo de Oro, Moll $(1996,33)$ habla de «una tirada normal de 1.500 ejemplares». El dato explica el enfado ante el «hurto» o «préstamo» involuntario de uno de los escasos 50 libros del Buscón llegados a Madrid.

${ }^{78}$ Historia de la vida del Buscón: el título presenta redacciones diferentes en las cuatro versiones variantes descritas por Rey $(2007,2009)$, y será transformado en los volúmenes de obras en prosa de Quevedo en los que se integra el relato: La vida del Buscavida, por otro nombre don Pablos (manuscrito de Santander); La vida del Buscón, llamado don Pablos (manuscrito de la RAE); Historia de la vida del Buscón, llamado don Pablos, ejemplo de vagamundos y espejo de tacaños (primera edición de Zaragoza, 1626, y Lázaro Galdiano, «manuscrito Bueno»). Fernández-Guerra (1852, 485-486) llamó la atención sobre la falta de respeto de impresores y lectores hacia su título, señalando que la obra «es conocida con el nombre de Historia y vida del gran Tacaño», y remitiendo al «Tribunal de la justa venganza, pág. 41» (p. LXXXV). Sobre este asunto, véanse Rey (2010b) y Alonso Veloso (2015, 123-124). 
to, nativo de su genio-, hube uno dellos por mano de un teatino ${ }^{79}$, con los mayores afanes del mundo, y pagué ocho reales por él ${ }^{80}$. Y habiéndole leído, vino un entendido déstos y, con los mayores ruegos del mundo, me lo llevó, asegurándome que hoy a mediodía estaría en casa; y hasta las diez de la noche le he aguardado, con la terciana rigurosísima y con una mohína muy grande, con que me he resuelto a escribir a V. S. y decirle que irá ${ }^{81}$ el martes que viene. No le espere V. S. con el aplauso que han merescido otras obras suyas, porque es la cosa más lánguida que ha visto en su vida, porque se revuelca en todo lo que ha dicho antes en diferentes obrillas ${ }^{82}$ y con poquísima gracia: al fin, los ingenios tienen su puericia, adolescencia, juventud, virilidad y senectud $^{83}$; y en este último paraje se hallan cuantos hoy conozco en Madrid, pues o no escriben o lo que escriben es sin aquella gracia primera ${ }^{84}$.

Beso a V. S. la mano mil veces por el favor del chocolate, que yo usaré dél con la moderación que V. S. me manda y buscaré a la persona que lo trae; y a

79 teatino: el término, que inicialmente designa a los miembros de la Orden de Clérigos Regulares, fundada en Roma en 1524, adquiere un valor peyorativo acreditado en dichos o refranes y textos literarios; los primeros jesuitas llegados a España recibieron el sobrenombre de teatinos. Pueden recordarse los versos de Góngora contra el padre Juan de Pineda «No más judicatura de teatino / cofre digo, overo con bonete / que tiene más de tea que de tino» (vv. 12-14), pertenecientes al poema titulado «Al padre Pineda, porque no le dio premio en un certamen», «En justa injusta, expuesto a la sentencia»; y referencias despectivas de Quevedo en Buscón o Carta de un cornudo a otro.

${ }^{80}$ ocho reales por él: en la impresión zaragozana no consta tasa con precio de venta de los ejemplares impresos por Vergés. Una pragmática de 1558 estableció las condiciones para la publicación en los reinos de Castilla, extendidas ulteriormente (a principios del siglo XVIII) a la Corona de Aragón. En ella se establecía la composición de los preliminares legales, entre los cuales figuraba la tasa: el Consejo fijaba el precio de venta de cada pliego del libro, tasa certificada por un escribano del mismo; según recuerda Moll $(1979,54)$, «en los reinos de Castilla se prohibió la entrada a toda obra impresa fuera de los mismos, a no ser que tuviese licencia del Consejo para circular en ellos y, a su vez, se le hubiese fijado la tasa». Sobre este precio, desmesurado en comparación con las tasas usuales en la época, véanse las pp. 70-71 del presente artículo.

81 irá: el libro, porque se lo enviará el martes próximo.

${ }^{82}$ obrillas: hasta la publicación del Buscón, Quevedo había divulgado sobre todo obras breves burlescas.

${ }^{83}$ puericia, adolescencia, juventud, virilidad y senectud: la división de las distintas edades del hombre en el siglo XVII fluctúa entre los distintos autores, pero suelen distinguirse aun dos etapas más, situadas, respectivamente, al principio y al final de la vida; según Autoridades, «la vida del hombre se divide en siete términos o edades, que son niñez, puericia, adolescencia, juventud, virilidad, vejez y decrepitud».

${ }^{84}$ en este último paraje [...] aquella gracia primera: a la altura de 1626 (o 1625), cuando parece haberse escrito este «aviso», la mayoría de los más importantes ingenios de la época que florecieron en el ámbito de la Corte madrileña son ya ancianos: Cervantes, nacido en 1547, había fallecido en 1616; Góngora, nacido en 1561, moriría en 1627; Lope viviría entre 1562 y 1635. Góngora tenía entonces 64 años, y Lope 63; Quevedo era el más joven, pero ya tenía 45. 
vueltas $^{85}$ de tantas cosas como suplico a V. S., podría mandarme algo de su gusto en esta corte ${ }^{86}$, pues sabe V. S. con el que le he de servir y vivir con el título de criado de V. S. toda mi vida. La de V. S. guarde Dios los años que yo deseo y he menester. Madrid y diciembre, 9, de $1626^{87}$.

Dé V. S. ${ }^{a}$ gracias a Dios que, por el mal tiempo, vino tarde el correo de ahí y no ha partido hasta hoy, con que ha habido lugar de enviar el libro. En él verá V. S. una casa de pupilaje pintada prolijísimamente y sin gracia $^{88}$, una estafa en la venta de Viveros pesada y sin sal ${ }^{89}$, unas matracas en Alcalá asquerosísimas ${ }^{90}$; traída por los cabellos y pesada, una introdución de un arbitrista, un diestro y un poeta $^{91}$, y la premática fría ${ }^{92}$; una casa del verdugo de Segovia malísima ${ }^{93}$, una introdución de un escudero forzada, y la vida dellos enfadosa de leer ${ }^{94}$; un caba-

${ }^{85}$ a vueltas: 'a vuelta de correo'. A vuelta, $u$ de vuelta: «Modo adverbial que vale lo mismo, que en volviendo, y así se dice A vuelta de correo o a vuelta de viaje» (Autoridades).

86 mandarme algo de su gusto en esta corte: el destinatario no reside en Madrid, de ahí que el remitente de la carta le informe de las novedades con sus «avisos».

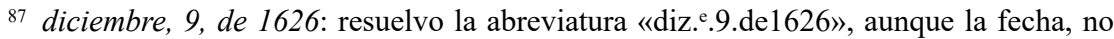
del todo nítida, podría ser la menos probable de 1625 .

${ }^{88}$ una casa de pupilaje pintada prolijísimamente y sin gracia: se refiere al capítulo 1, 3, «De cómo fui a un pupilaje por criado de don Diego Coronel» (cito por la edición de la princeps de 1626 a cargo de Rey 2010a, 29-40). Sorprende la acusación de prolijidad en la descripción de la casa de Cabra, sobre todo si se compara con otros relatos picarescos previos como el Guzmán de Alfarache.

89 una estafa en la venta de Viveros pesada y sin sal: el episodio de la venta de Viveros se encuentra justo a continuación, en el siguiente capítulo $(1,4,41-50)$, cuando dejan la casa de pupilaje y el relato trata «de la convalecencia y ida a estudiar a Alcalá de Henares». Este capítulo es uno de los que concentra más críticas en las invectivas contra el Buscón, particularmente el Memorial y Tribunal de la justa venganza.

${ }^{90}$ unas matracas en Alcalá asquerosísimas: el capítulo siguiente $(1,5,51-60)$ trata «de la entrada de Alcalá, patente y burlas que me hicieron por nuevo». El calificativo «asquerosísimo» concuerda con el contenido del episodio, donde Pablos recibe un baño de escupitajos y despierta «sucio hasta las trencas».

${ }^{91}$ una introdución de un arbitrista, un diestro y un poeta: el anónimo comentarista no parece tener objeción alguna sobre los dos siguientes capítulos, que comprenden, entre otros asuntos, la noticia de la muerte del padre y la resolución que adopta el pícaro de separarse de sus familiares, pues alude a 1, 8, titulado «Del camino de Alcalá para Segovia y lo que me sucedió en él hasta Rejas, donde dormí aquella noche» (79-87) y 1, 9, «De lo que me sucedió, hasta llegar a Madrid, con un poeta» (89-94).

92 y la premática fría: siguiendo el curso del relato, apunta ahora al capítulo 1,10 , «De lo que hice en Madrid y lo que me sucedió hasta llegar a Cercedilla, donde dormí», donde Pablos lee la Premática contra los poetas güeros, chirles y hebenes.

${ }_{93}^{3}$ una casa del verdugo de Segovia malísima: el capítulo siguiente, 1, 11, discurre en efecto sobre el hospedaje del pícaro en casa de su tío, el cobro de la hacienda heredada de su padre (ajusticiado por Alonso Ramplón) y su vuelta a la corte.

${ }^{94}$ una introdución de un escudero forzada, y la vida dellos enfadosa de leer: alude a los dos últimos capítulos del libro primero $(1,12$ y 1,13$)$ : «De mi huida y los sucesos en 
llero fingido, un pobre, un comediante y un devoto de monjas ${ }^{95}$. Que, siendo el fin de satirizar todos estos estados ${ }^{96}$-en que él otras veces ha dicho maravillas-, en este libro dice maravillosas frialdades ${ }^{97}$. Puede ser que este voto sea tan malo con el humor melancólico ${ }^{98}$ que gasto con esta infame terciana. V. S. ${ }^{a}$ lo leerá, y es cierto que valdrá el libro tanto cuanto V. S. ${ }^{\text {a }}$ lo estimare o desestimare. El Buscón se fue a las Indias, y no querría que desde allí nos lo trujese el auctor en la segunda parte, que sería peor que el pajarero del rey ${ }^{99}$, que compuso aquí ${ }^{100}$ un libro mayor que el Flos Sanctorum ${ }^{101}$ del canto de los pájaros y ponía distintamente los pasajes de cada uno, y decía que el jilguero tenía un chirrí102 y dos chiculios ${ }^{103}$; y el pardillo, dos cho cho ${ }^{104}, \&$. ¡Y promete segunda parte del libro...! ${ }^{105}$

ella hasta la corte» y «En que el hidalgo prosigue el camino, y lo prometido de su vida y costumbres».

${ }^{95}$ un caballero fingido, un pobre, un comediante y un devoto de monjas: sintetiza rápidamente lo que en la edición de 1626 forma parte del libro segundo (en otros testimonios, como el manuscrito $B$, consta una división tripartita): capítulos 2, 1-2, 8; y 2, 9 («En que me hago representante, poeta y galán de monjas, cuyas propriedades se descubren lindamente»).

${ }^{96}$ satirizar todos estos estados: alusión a la sátira de estados y la revista satírica de tipos usual en la narrativa picaresca, favorecida por la itinerancia del protagonista.

${ }^{97}$ frialdades: «Significa también necedad, dicho o despropósito, sin gracia ni viveza, que deja frío al que lo oye» (Autoridades).

98 humor melancólico: sobre las connotaciones negativas asociadas a este tipo de humor, uno de los cuatro reconocidos en la época, y su evolución, puede consultarse Aladro (2005, 577-581).

${ }_{99}$ el pajarero del rey: los jardines del parque del Retiro, ideados en 1629 por Olivares como espacio de recreo de Felipe IV y construidos entre 1630 y 1640, se asentaron en el entorno del monasterio de los Jerónimos y albergaron un palacio, además de otras instalaciones, entre las que había una pajarera de grandes dimensiones con aves exóticas para su exhibición. No he encontrado referencias a un pajarero real. Sobre la pajarera, véase Brown y Elliott $(2003,226)$.

100 aquí: el adverbio de lugar parece situar nuevamente a remitente y destinatario en lugares diferentes.

101 el Flos Sanctorum: no he podido localizar ese libro tan voluminoso dedicado a las aves. Como es sabido, las Flores sanctorum son traducciones españolas de la Legenda Aurea de Jacobo de Vorágine, célebre colección hagiográfica; destacan, en esta época, las de Pedro de Ribadeneyra (en tres volúmenes publicados en 1599, 1601 y 1604) y la de Alonso Villegas.

102 chirrí: aunque el chirrí es un ave, parece referirse a un tipo concreto de canto, como el descrito por Azara (1805, 369-370).

103 chiculios: Vida y hechos de Estebanillo González, 5: «hablaba bernardinas y echaba chiculios».

104 cho cho: parece duplicación de la interjección cho: «Voz de que se sirven los arrieros, gañanes y gente del campo, para que paren, y se detengan las cabalgaduras» (Autoridades).

105 en la segunda parte [...] Y promete segunda parte del libro: como ya constató Astrana (1932, XXIV), resulta extraño que el autor de la carta mencione la anunciada segunda parte del Buscón, referencia final que se encuentra en la tradición manuscrita, pero no en la 


\section{BIBLIOGRAFÍA CITADA}

Aladro Font, Jorge. 2005. «La melancolía de Alonso Quijano "el Bueno"». Príncipe de Viana 66 (236): 577-588. http://www.culturanavarra.es/uploads/files/01_PV236-0577. pdf

Aldea Vaquero, Quintín. 1986. España y Europa en el siglo XVII. Correspondencia de Saavedra Faxardo, Tomo I, 1631-1633. Madrid: CSIC.

Aldea Vaquero, Quintín. 1997. El cardenal infante don Fernando o la formación de un príncipe de España. Madrid: Real Academia de la Historia.

Alonso Veloso, María José. 2015. «Los títulos de Quevedo». La Perinola 19: 111-148. https://revistas.unav.edu/index.php/la-perinola/article/view/1998

Alonso Veloso, María José. 2017a. «Noticia sobre un manuscrito de El Tribunal de la justa venganza». Revista de Filología Española XCVII (1): 9-34. https://doi.org/10.3989/ rfe.2017.01

Alonso Veloso, María José. 2017b. «Una invectiva inédita contra Gracias y desgracias del ojo del culo de Quevedo». Neophilologus 101 (4): 523-540. https://doi.org/10.1007/ s11061-017-9532-x

Alonso Veloso, María José. 2020a. «La respuesta de Quevedo al padre Pineda: una obra posiblemente censurada». Neophilologus 104 (1): 49-67. https://doi.org/10.1007/s11061019-09610-z

Alonso Veloso, María José, ed. 2020b. Al padre Juan de Pineda, de la Compañia de Jesús. En Francisco de Quevedo, Obras completas en prosa, dir. Alfonso Rey, coord. M. José Alonso Veloso, vol. VIII, 127-250. Barcelona: Castalia.

Alonso Veloso, María José. En prensa a. «Una diatriba manuscrita inédita contra Política de Dios de Quevedo», Revista de Filología Española.

Alonso Veloso, María José. En prensa b. «Quevedo censurado: la denuncia que forzó la reescritura de Política de Dios». Bulletin of Spanish Studies.

Alonso Veloso, María José, ed. En prensa c. Respuesta al libro intitulado Política de Dios, gobierno de Cristo, tiranía de Satanás.

Astrana Marín, Luis, ed. 1932. Obras completas de Quevedo. Obras en verso. Madrid: Aguilar.

Astrana Marín, Luis, ed. 1946. Epistolario completo de don Francisco de Quevedo Villegas. Madrid: Instituto Editorial Reus.

Azara, Félix de. 1805. Apuntamientos para la historia natural de los pájaros del Paraguay y Río de la Plata, t. 2. Madrid: Imprenta de la Hija de Ibarra.

Brown, Jonathan y John H. Elliot. 2003. Un Palacio para el Rey: el Buen Retiro y la corte de Felipe IV, trad. Vicente Lleó y María Luisa Balseiro. Madrid: Taurus.

Cabo Aseguinolaza, Fernando, ed. 1993. Francisco de Quevedo, La vida del Buscón. Barcelona: Crítica.

Cabo Aseguinolaza, Fernando. 2009. «El Buscón a la luz de los Quijotes». La Perinola 13: 229-248. https://revistas.unav.edu/index.php/la-perinola/article/view/27918

Cabo Aseguinolaza, Fernando. 2011. «Cosas de la edad: notas sobre la fecha del Buscón». Ínsula 778: 31-34.

princeps zaragozana ni las ediciones de ella derivadas. O bien era conocedor de otras versiones manuscritas de la obra, o bien, como parece más plausible, tuvo entre sus manos una edición diferente, divergente al menos en ese aspecto. 
Castellanos, Basilio Sebastián, ed. 1843. Obras de don Francisco de Quevedo Villegas, II. Madrid: Establecimiento tipográfico.

Castilla Soto, Josefina y Justina Rodríguez García. 2011. Historia moderna de España (1469-1665). Madrid: Editorial Universitaria Ramón Areces.

Cros, Edmond, ed. 1988. Francisco de Quevedo, Historia de la vida del Buscón. Madrid: Taurus.

Díaz Migoyo, Gonzalo. 2003. «Las fechas del Buscón». En Estudios sobre el Buscón. Editado por Alfonso Rey, 19-36. Pamplona: Eunsa.

Elliott, John. 1990. El Conde-Duque de Olivares. El politico en una época de decadencia. Barcelona: Crítica.

Elliott, John. y José Francisco de la Peña. 1978. Memoriales y cartas del conde duque de Olivares, tomo I. Politica interior: 1621 a 1627. Madrid: Alfaguara.

Enciso Recio, Luis Miguel. 2005. «La corte de dos mundos». En Felipe IV: el hombre y el reinado, coord. José Alcalá Zamora y Queipo de Llano. Madrid: Real Academia de la Historia - Centro de Estudios Europa Hispánica.

Ettinghausen, Henry. 2012. «Pellicer y la prensa de su tiempo». Janus 1: 55-88. http://www. janusdigital.es/articulo.htm?id=9

Ettinghausen, Henry. 2015. How the press began: the pre-periodical printed news in Early Modern Europe. A Coruña: SIELAE.

Ettinghausen, Henry y Manuel Borrego, ed. 2001. Andrés de Almansa: Obra periodística. Madrid: Editorial Castalia.

Fernández-Guerra y Orbe, Aureliano, ed. 1852-1859. Obras de don Francisco de Quevedo Villegas. Madrid: M. Rivadeneyra.

Gutiérrez, Carlos María. 2005. La espada, el rayo y la pluma: Quevedo y los campos literarios y de poder. West Lafayette, Ind.: Purdue University Press.

Jauralde Pou, Pablo, ed. 1990. El Buscón. Madrid: Castalia.

Jauralde Pou, Pablo. 1999. Francisco de Quevedo (1580-1645). Madrid: Castalia.

Lázaro Carreter, Fernando, ed. 1965. La vida del Buscón llamado don Pablos. Salamanca: CSIC.

Martín Jiménez, Alfonso. 2008. «El Buscón de Quevedo, la Vida de Pasamonte y el Quijote de Avellaneda». La Perinola 12: 123-144.

Moll, Jaime. 1974. «Diez años sin licencias para imprimir comedias y novelas en los reinos de Castilla: 1625-1634». Boletín de la Real Academia Española 54: 97-103.

Moll, Jaime. 1979. «Problemas bibliográficos del libro del Siglo de Oro». Boletín de la Real Academia Española 59 (216): 49-108.

Moll, Jaime. 1996. «El impresor y el librero en el Siglo de Oro». En El Mundo del libro antiguo, coordinado por Francisco Asín, 27-42. Madrid: Universidad Complutense.

Moll, Jaime. 2008. «La narrativa castellana a comienzos del siglo XVII: aspectos editoriales». Anales Cervantinos XL: 31-46. https://doi.org/10.3989/anacervantinos.2008.001

Ochoa Brun, Miguel Ángel. 2006. Historia de la diplomacia española. La edad barroca, I, vol. VII. Madrid: Ministerio de Asuntos Exteriores y Cooperación.

Páez de Valenzuela, Juan. 1624. Relación del recibimiento, hospedaje y fiestas que el marques del Carpio, Gentilhombre de su magestad hizo al rey don Felipe IV nuestro señor en su estado y villas del Carpio y Adamuz y cacería de sus montes, lunes a los diez y nueve del mes de febrero deste presente año de 1624. Córdoba: Salvador de Cea Tesa.

Pizarro Llorente, Henar. 2004. Un gran patrón en la corte de Felipe II: don Gaspar de Quiroga. Madrid: Universidad Pontificia de Comillas. 
Plata Parga, Fernando. 2019. «La zurriaga de Perinola: edición crítica de un texto inédito contra Quevedo». La Perinola 23: 85-127. https://doi.org/10.15581/017.23.85-127

Puyol Bull, Carlos. 1993. Inquisición y política en el reinado de Felipe IV. Madrid: CSIC.

Rey, Alfonso. 1994-1995. «Quevedo, Duport y la edición del Buscón». Journal of Hispanic Research 3: 167-179.

Rey, Alfonso. 1997. «Más sobre la fecha del Buscón». En Quevedo a nueva luz: Escritura y politica, coord. Antonio Carreira y Lía Schwartz, 151-164. Málaga: Universidad de Málaga.

Rey, Alfonso. 1999. «Para una nueva edición crítica del Buscón». Hispanic Review 67 (1): 17-35.

Rey, Alfonso. 2007a. «Introducción al volumen II. Relato picaresco». En Francisco de Quevedo, Obras completas en prosa, dir. Alfonso Rey, vol. II, t. I. Madrid: Castalia.

Rey, Alfonso. 2007b. «Quevedo y las revisiones del Buscón». Sociocriticism 22: 119-152.

Rey, Alfonso, ed. 2007c. El Buscón. Edición crítica de las cuatro versiones. Madrid: CSIC.

Rey, Alfonso, ed. 2010a. El Buscón. Zaragoza: Institución «Fernando el Católico».

Rey, Alfonso. 2010b. «The Title of the Buscón: Textual Problems and Literary Aspects». Modern Language Review 105: 122-130.

Rey, Alfonso. 2014. Lectura del «Buscón». Valladolid: Ediciones Universidad de Valladolid.

Reyes Gómez, Fermín de los. 2010. «La estructura formal del libro antiguo español». $P a-$ ratesto 7: pp. 9-59.

Rivas Albadalejo, Ángel. 2015. Entre Madrid, Roma y Nápoles. El VI Conde de Monterrey y el gobierno de la Monarquía Hispánica (1621-1653). Tesis doctoral. Universitat de Barcelona.

Rivero Rodríguez, Manuel. 1993. «Corte y "poderes provinciales”: el virrey Colonna y el conflicto con los Inquisidores de Sicilia». Cuadernos de Historia Moderna 14: 73-101.

Roncero López, Victoriano, ed. 2008. El tribunal de la justa venganza. Pamplona: EUNSA.

Selden Rose, Roberto, ed. 1927. Don Francisco de Quevedo y Villegas, Historia de la vida del Buscón. Madrid: Hernando.

Sénder, Ramón J. 1971. «Baroja y las contradicciones latentes». En Examen de ingenios. Los noventayochos, 209-272. Madrid: Aguilar.

Stradling, R. A. 1992. Europa y el declive de la estructura imperial española (1580-1720). Madrid: Cátedra.

Stradling, R. A. 2003. The Armada of Flanders: Spanish Maritime Policy and European War, 1568-1668. Cambridge: Cambridge University Press.

Tobar Quintanar, María José. 2010. «La última revisión quevediana del Buscón: la edición príncipe (Zaragoza, 1626)». La Perinola 14: 321-364.

Tobar Quintanar, María José. 2011-2012. «El Buscón: una obra juvenil de Quevedo». Archivum LXI-LXII: 445-474.

Tobar Quintanar, María José. 2018. «Incertidumbres y certezas en el problema textual del Buscón: sus implicaciones ecdóticas». Hipogrifo 6 (2): 757-776.

Vélez de Guevara, Luis. 2007. El Diablo Cojuelo. Ed. Enrique Rodríguez Cepeda. Madrid: Cátedra.

Fecha de recepción: 03 de octubre de 2017.

Fecha de aceptación: 25 de enero de 2018. 